\title{
تحقيق مبادئ التخطيط الحضري المستدام بمناطق الاسكان غير الرسمي على الزئ الاراضي الزراعية
}

\section{د. دانيا حيدر احمد المد}

الهيئة العامة للتخطيط العمر اني ـ وزارة الاسكان و المر افق و المجتمعات العمر انية الجديدة ـ القاهرة ـ مصر raniahieder78@gmail.com: البريد الاكتكروني

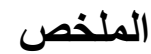

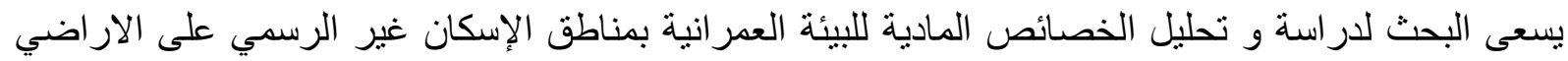

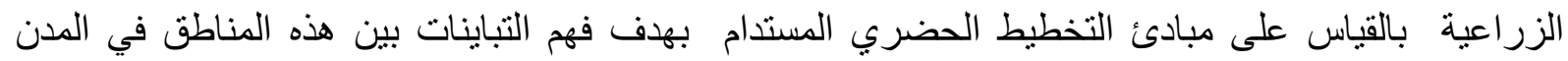

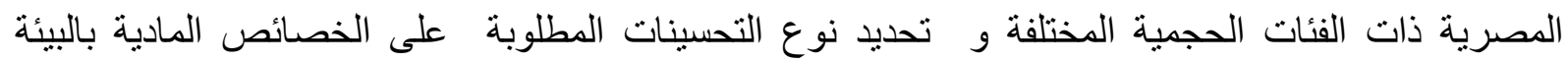

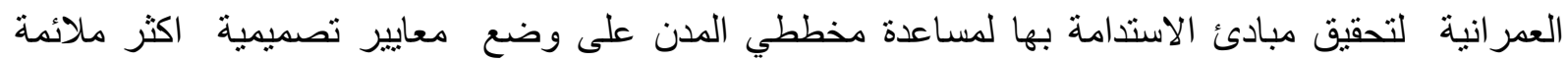

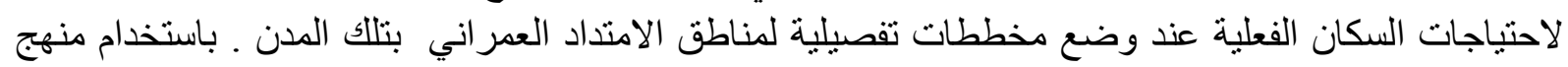

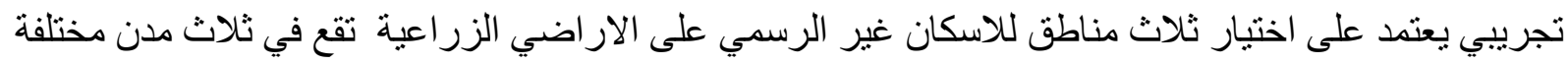
من حيث حجم السكان. و تحديد أهم الاختلافات بين المناطق بالمدن ذات الاحجام السكانية المختلفة بالقياس على مبادئ التخطيط

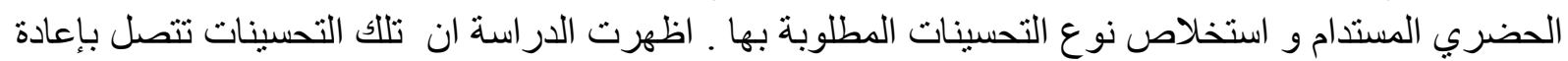

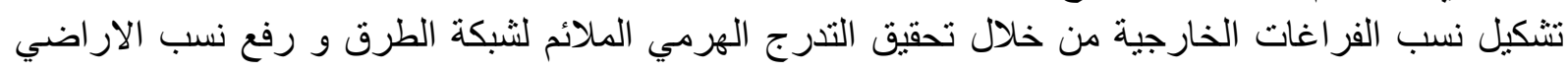

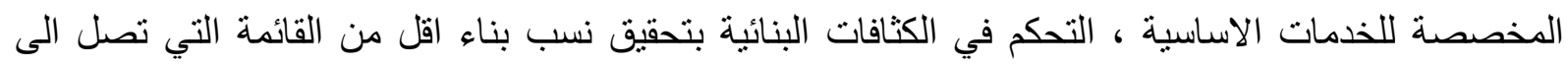

$$
\text { . \%1.. }
$$

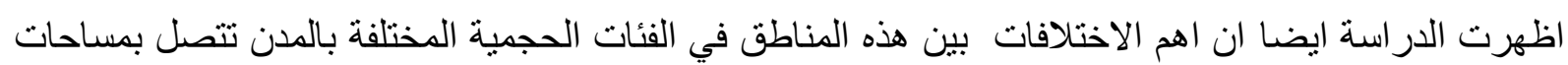

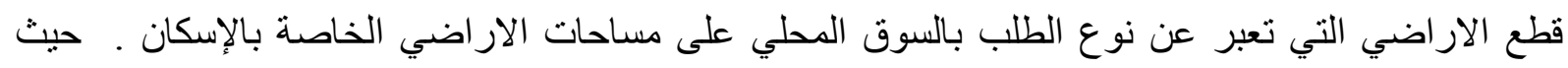

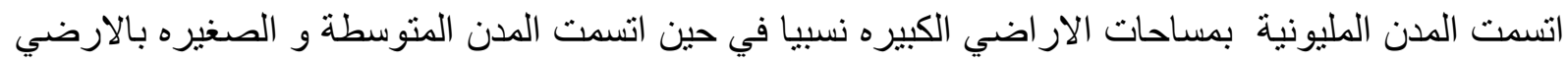

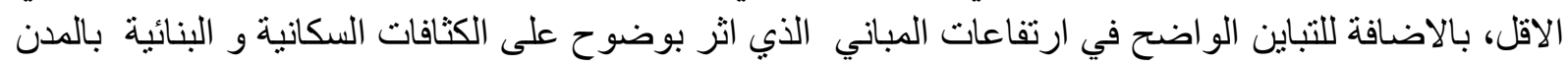

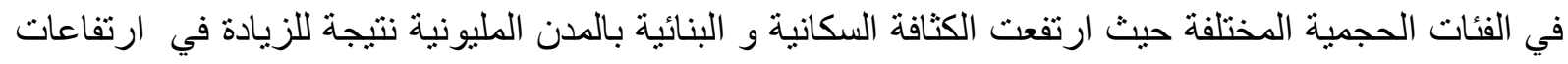

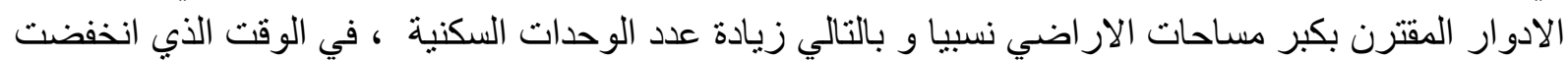

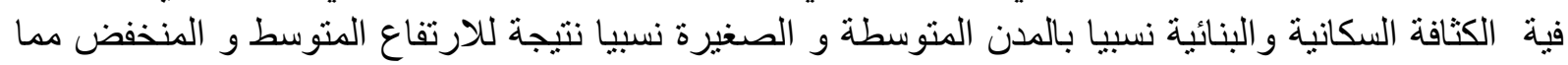

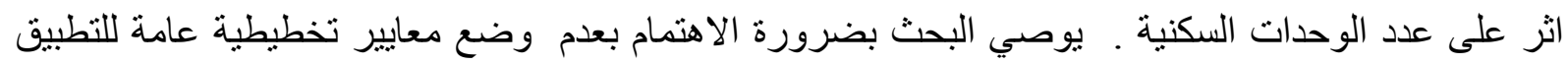

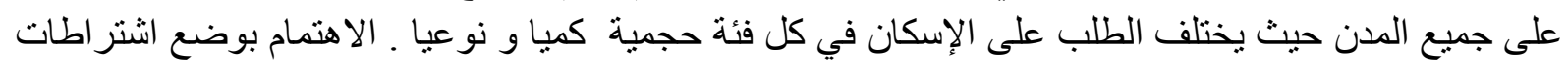

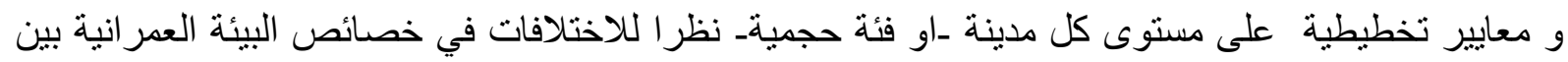

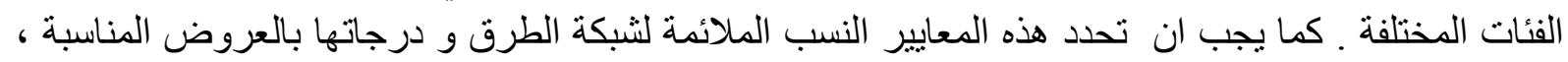

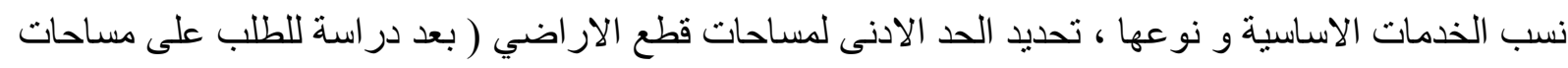
الاراضي المطلوبة، نسب البناء و قيود الارتفاع للتحكم في الكثافات السكانية و البنائية . لأنية

الكلمات المفتاحية : n - n

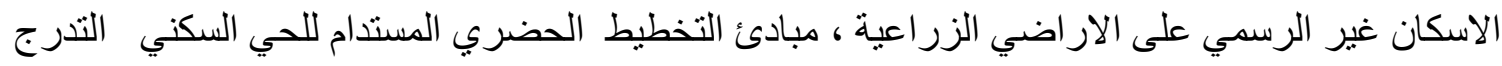

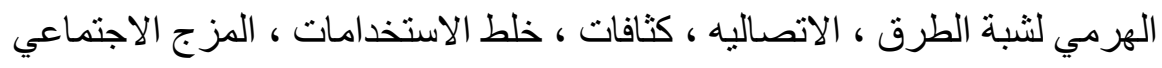




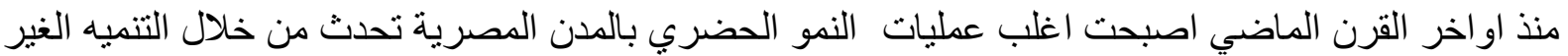

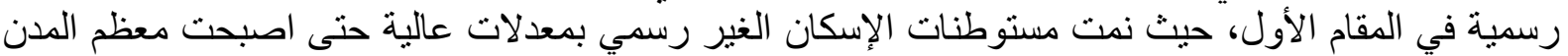

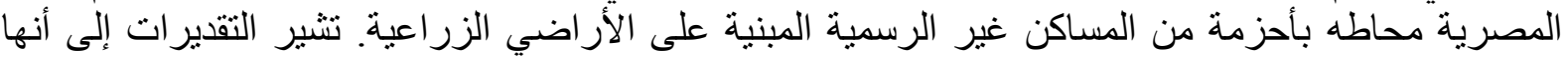

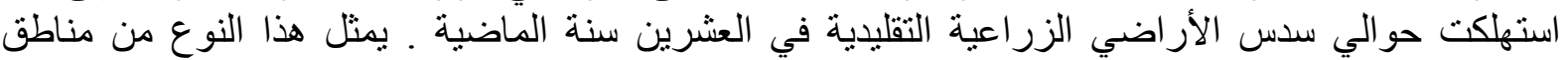

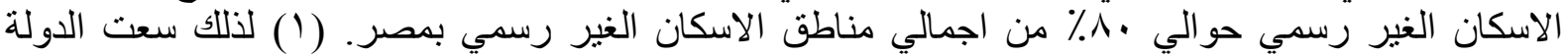

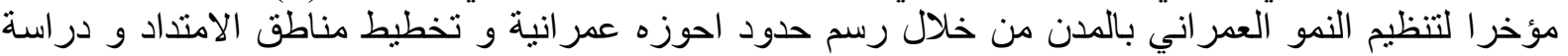

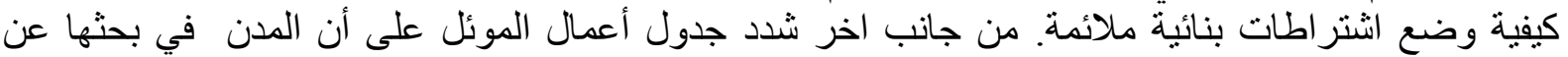

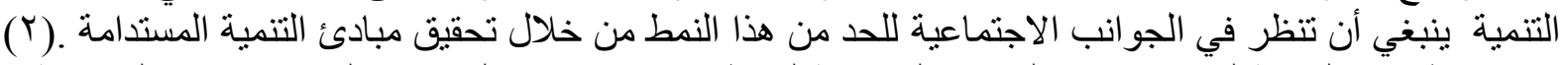

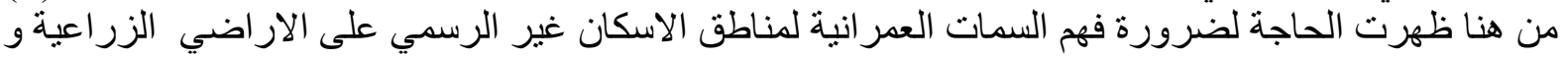

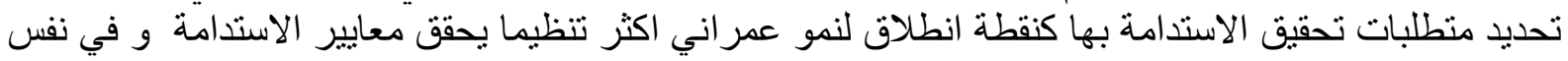
الوقت يحقق الاحتياجات الفعلية لسكان هذه المناطق ـ الطناق لن

منهجية البحث:

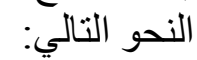
المرحلة الاولى : العتمد على استخدام المنهج الوصفي من خلال دراسة نظرية لمبادئ التخطيط الحضري المستدام على مستوى الحي السكني و تحديد معايير قياسه بشكل كمي. توضيح المقصود بمناطق لإنى الإسكان غير

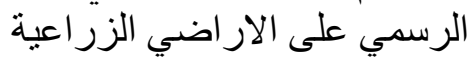
المرحلة الثانية : تعتمد على استخدام المنهج التحليلي في تحديد كيفية اختبار مناطق الدراسه على مستوى

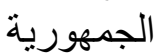

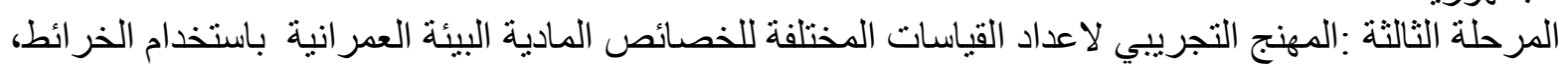

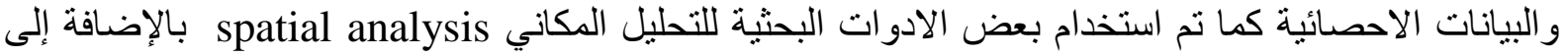

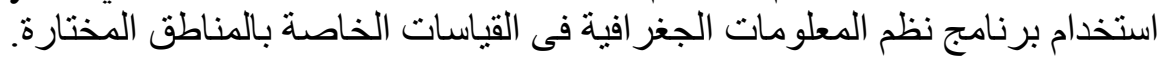

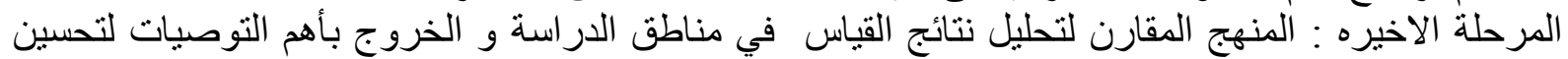

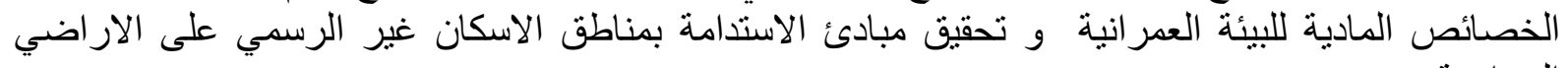

\section{ا - مبادئ التخطيط الحضري المستدام للحي السكني :}

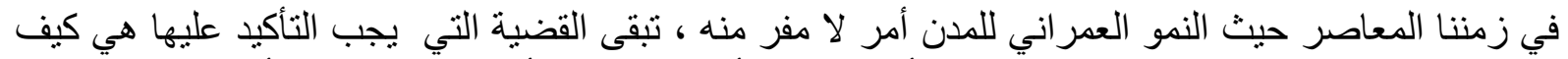

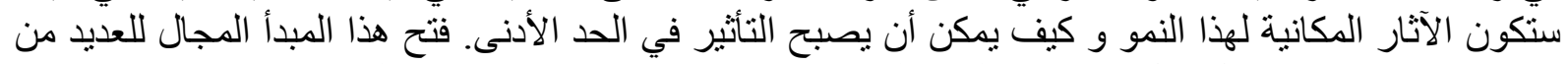

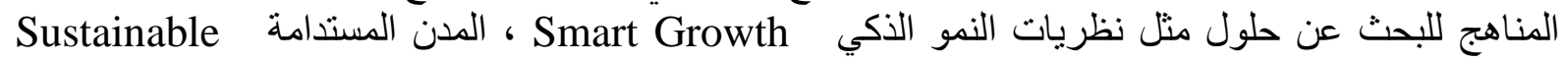

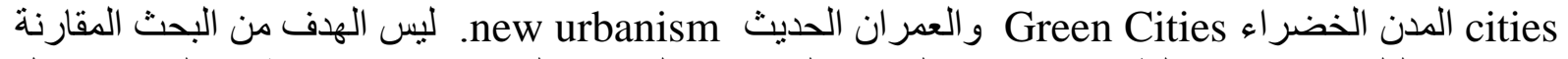

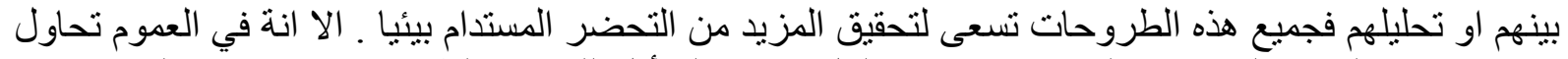

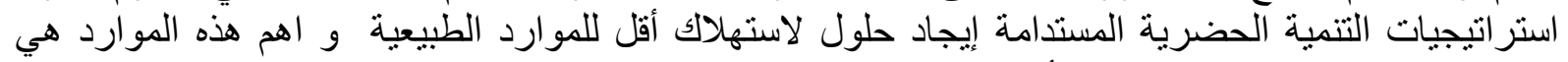

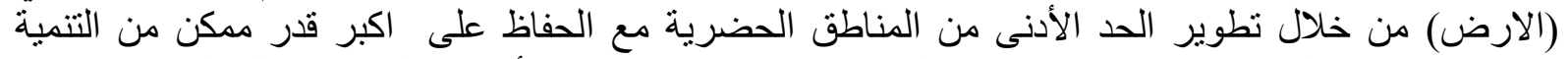

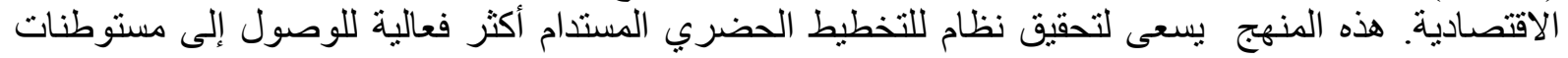

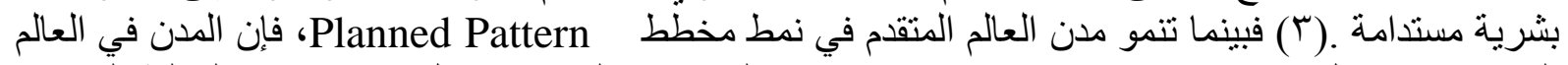

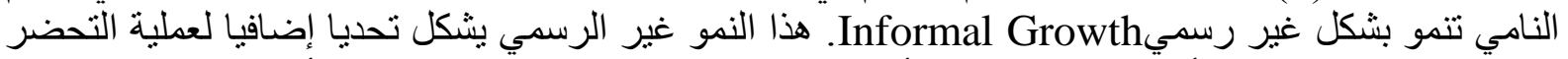

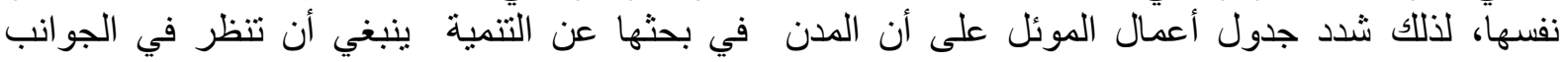

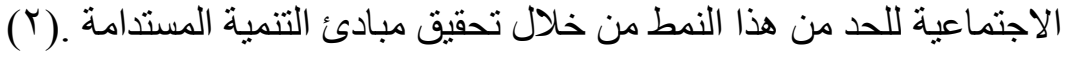




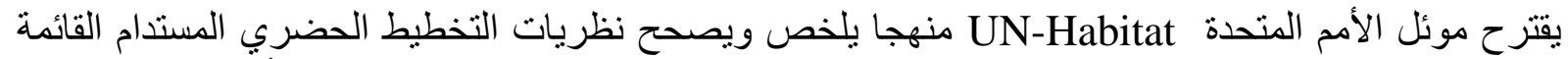

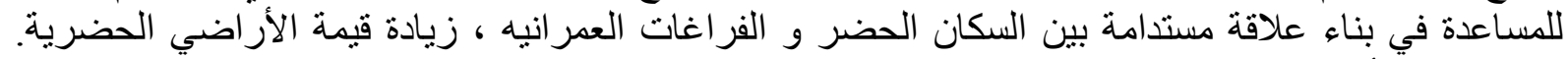

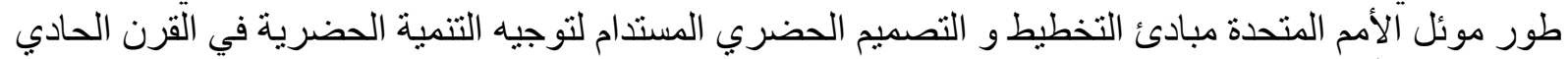
والعشرين. الأهداف الرئيسية لهذه المبادئ هي: (ع) يلخصها الجدول رقم (1)

Adequate Space For Streets And An Efficient توفير شبكة طرق فعالة وبمساحة مناسبة

Street

Connectivity تعزيز الاتصاليه

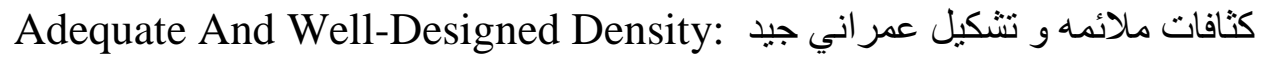

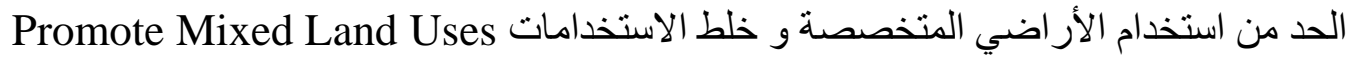

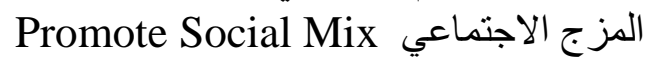

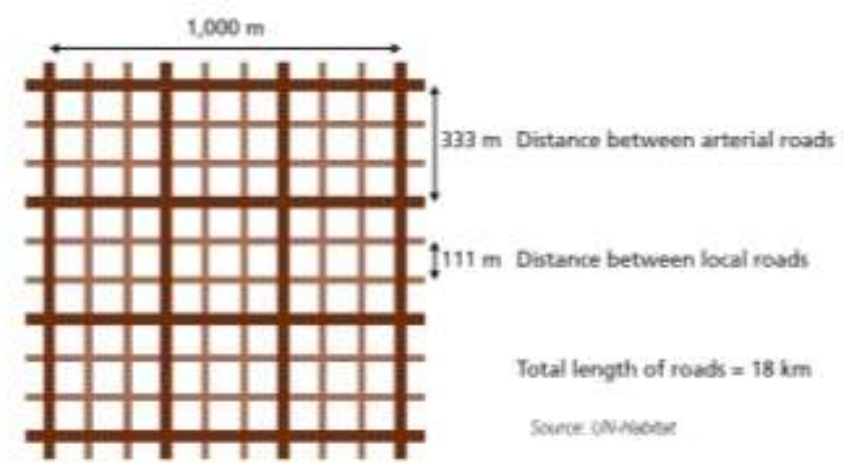

1- اتوفير شبكة شوارع فعالة بالتدرج الملائم

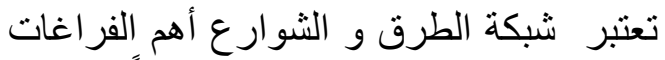

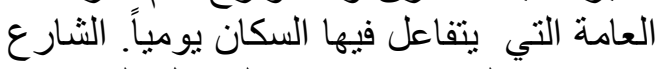
عنصر هيكلي يقوم بتحديد التشكيل الحضري

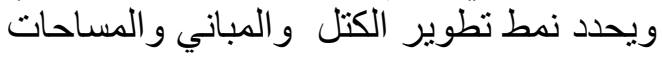

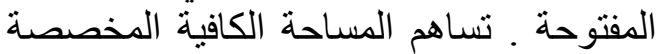

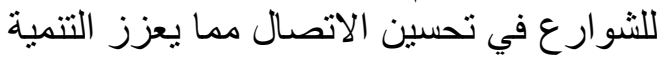
الاقتصادية. كمؤشر ، في البلدان النامية ، تكون الأني

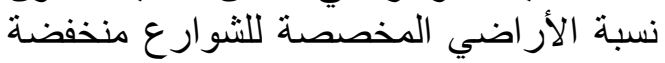
الشكل (1) نموذج لثبكة الشوارع لتحقيق تدرج هرمي ملائم

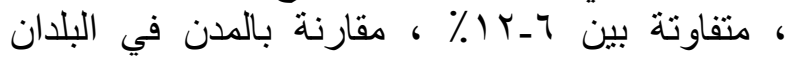
(UN-Habitat), 2016, p.95.: المصدر

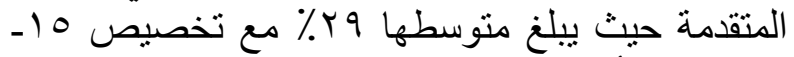

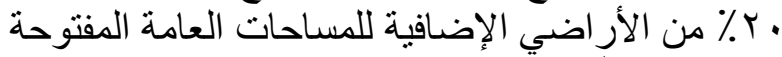

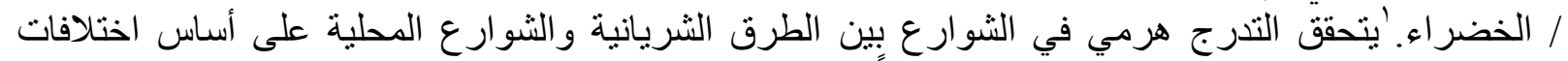

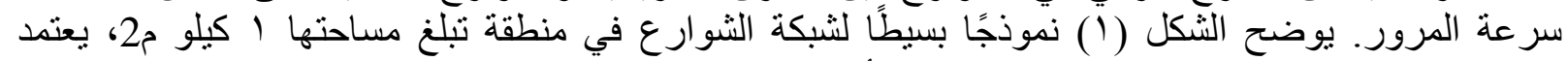

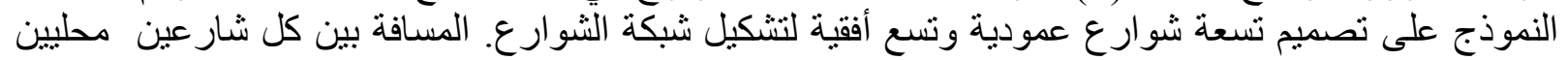

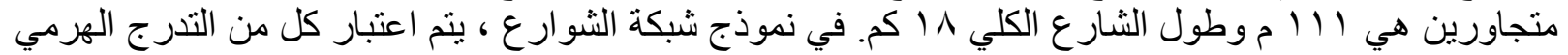

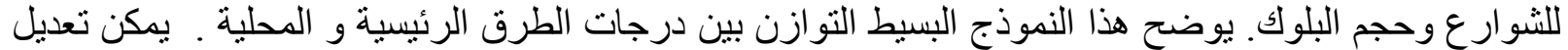

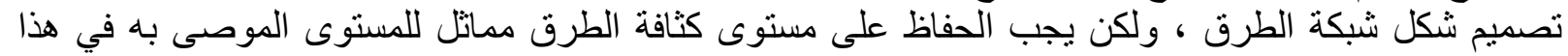

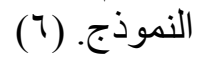

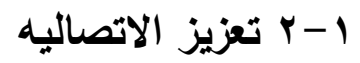

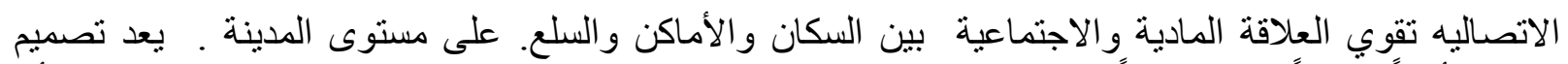

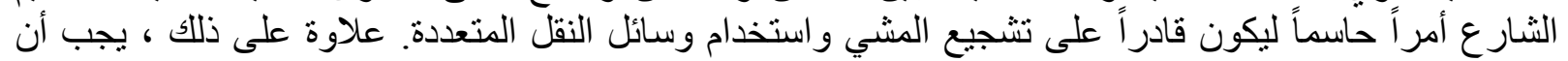

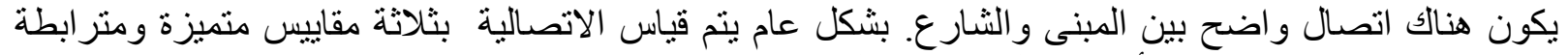

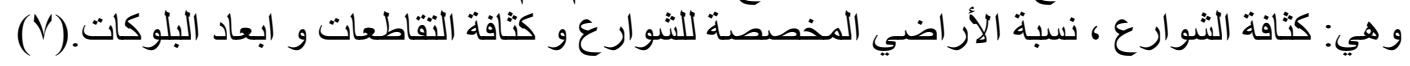
ا

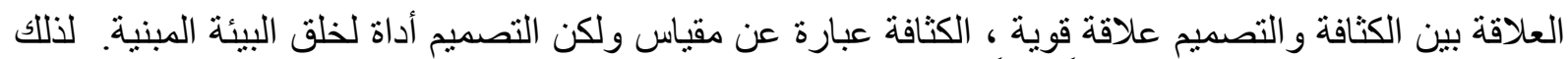

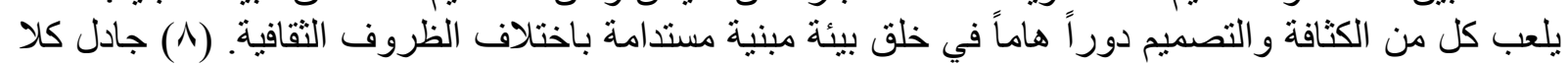

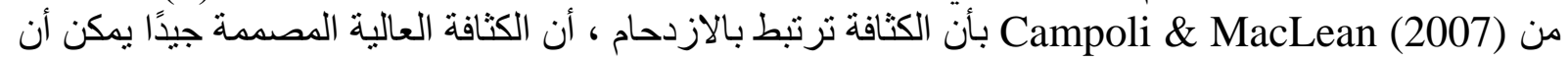


تحقق بيئة مبنية جيدة ويمكن أن توفر الأرض و الطاقة والتكلفة الإجمالية للبنية التحتية لتنمية الإسكان. الكثافة

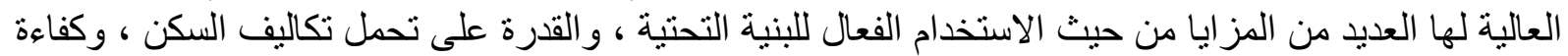

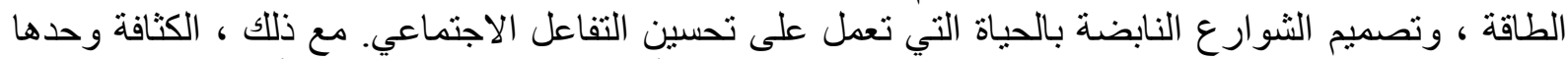

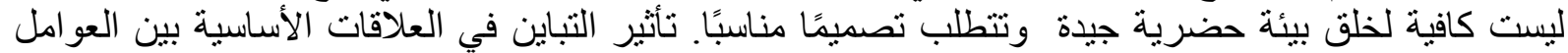

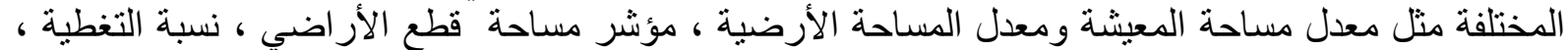

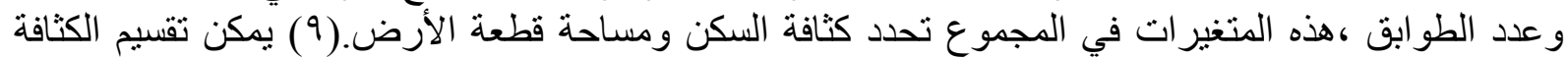

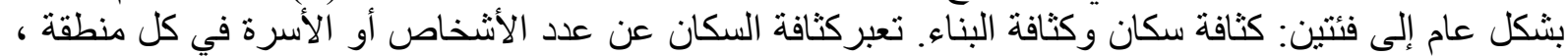

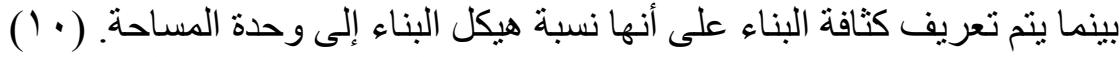

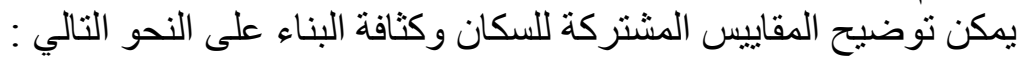

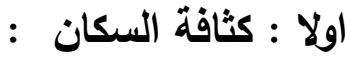

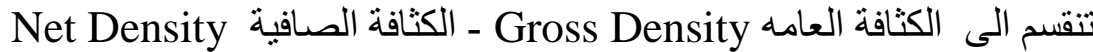
الكثافة العامه Gross Density: تتعامل مع المنطقة باكملها ، تأخذ في الاعتبار أيضًا المساحات غير السكنية

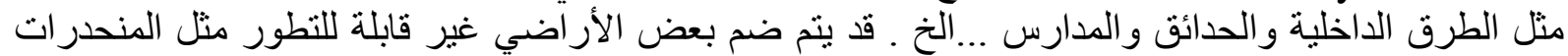
الثديدة مثنلا ـ هذا التناقض في الثمولية يؤدي إلى غموض كبير في قياس الكثافة ، وبالتالي يجعل المقارنة

(1) صعبة. (11) الكثافة السكنية الصافية) Net Density : لا لا يوجد تو افق حول تعريف الكثافة الصافية. فقد يشار للمنطقة السكنية

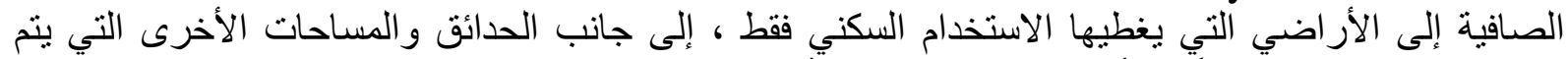

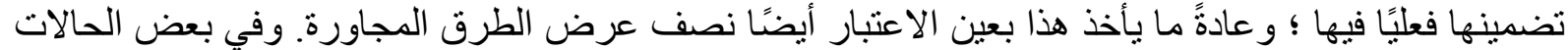

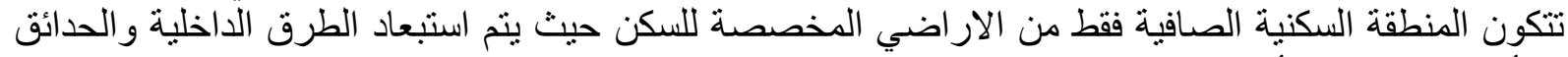

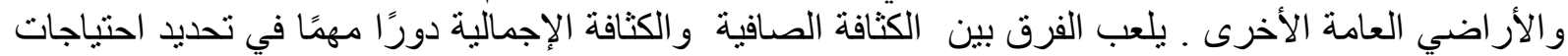

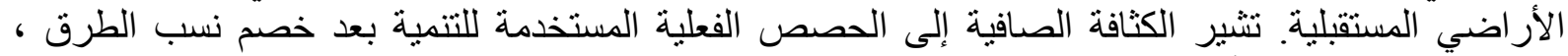

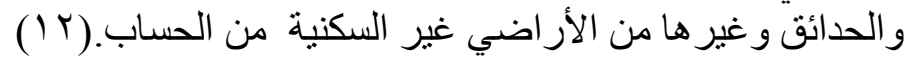
ثانيا : كثافة البناء تعبر كثافة البناء عن تركيز كتلة المباني في منطقة جغر افية معينة. من اكثر مقاييس كثافة البناء اهميه هي الكثافة

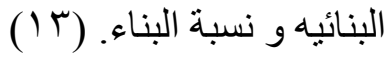
الكثافة البنائيه (Floor area ratio) هي أكثر المقاييس المستخدمه لمر اقبة كثافة البناء ، و هي أكثر تعقيداً من الكثافة السكنية تعتبر FAR ؛ و تقاس بإجمالي المساحة الأرضية للمبنى (بإضافة جميع مستو الإيات الطو ابق)

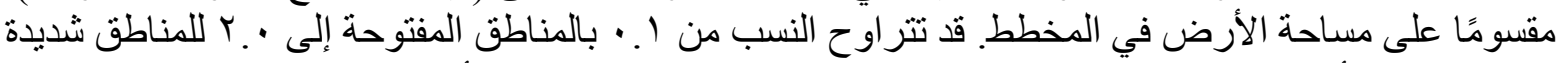

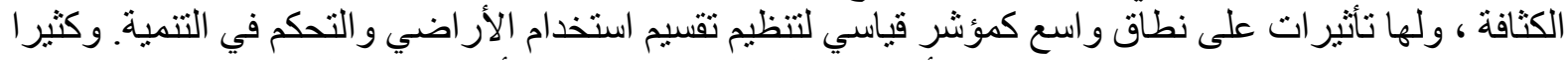

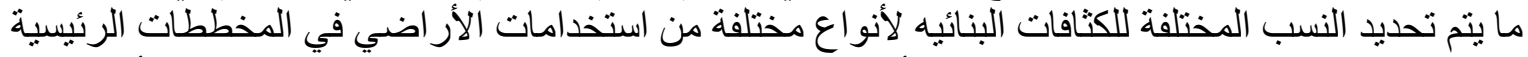

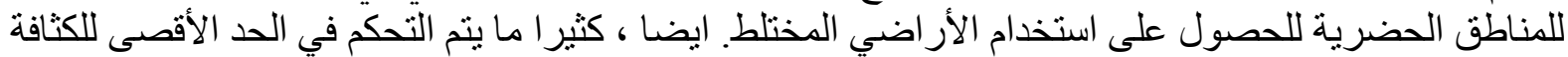
البنائيه من أجل التحكم في مدى التر اكم ومنع التنمية المفرطة التحن.

نسبة البناء (coverage ratio) : مقياس لنسبة المساحة التي يغطيها الجزء المبنى من الموقع ، غالباً ما

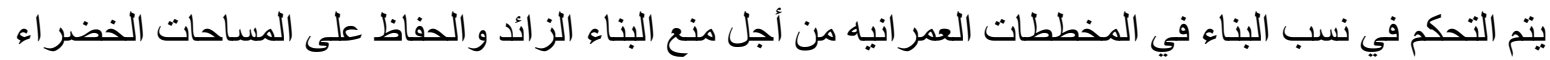

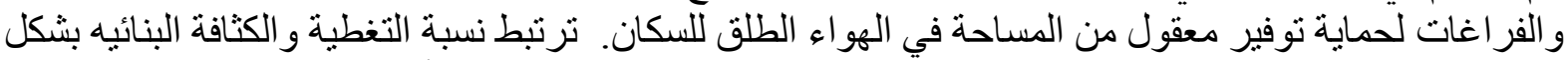
مباشر بشكل المبني وبالتالي توجد علاقة مباشرة الشة بين نسبة البناء ونسبة المساحة الأرضية.

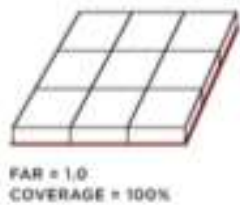

COVERAGE $* 100 x$

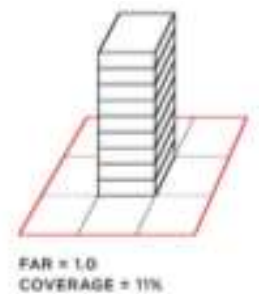

COVFRAeE $\rightarrow$ m

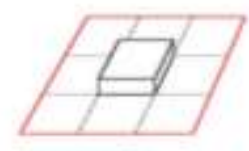

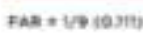

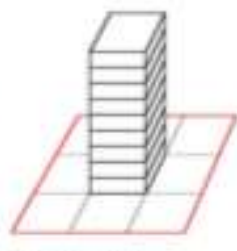

ThR * We ctes 
الثكل (ץ) العلاقة بين الكثافة البنائية ونسبة البناء

http://densityatlas.org/measuring/metrics.shtml: المصدر

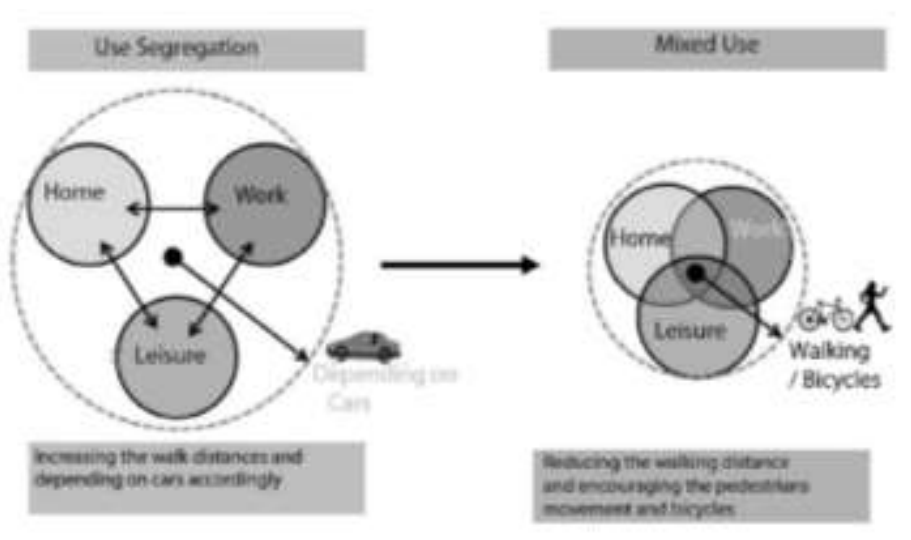

الثكل ( ب) مميزات خلط الاستعمالات

المصدر :. Nabil \& Eldayem (2015) p 288

Promote 1- الاستخدامات

Mixed Land Uses

بشكل عام ، يستخدم مصطلح استخدام

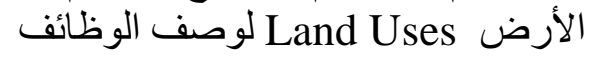

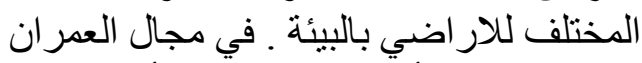
يميل استخدام الأراضي السائد إلى أن يكون

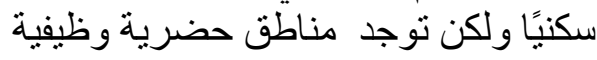

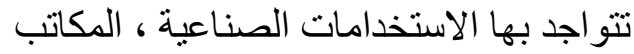

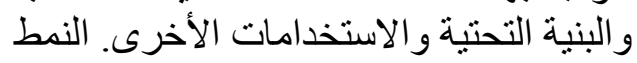

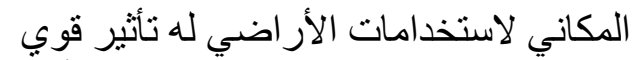

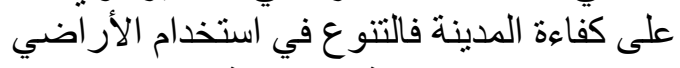

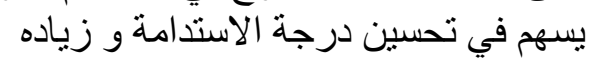

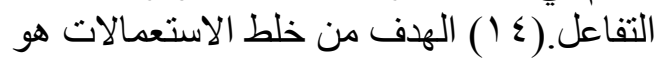

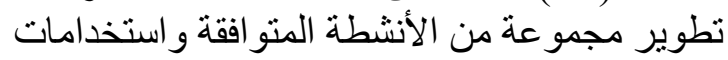

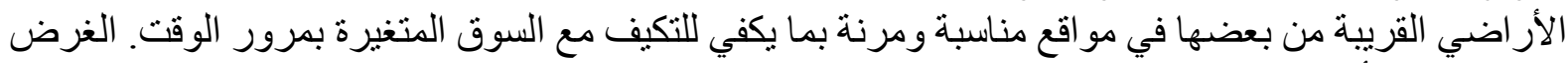

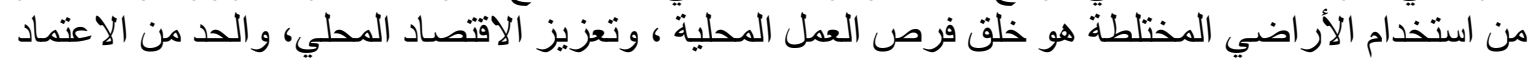

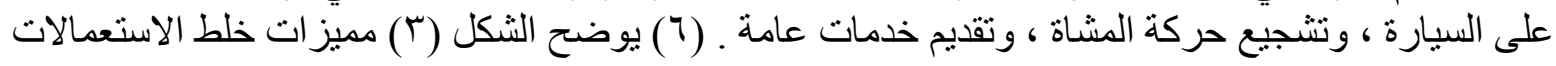

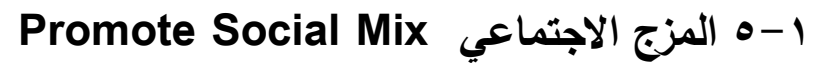

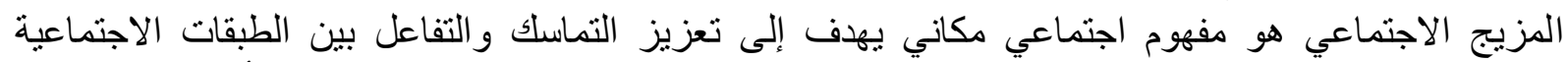

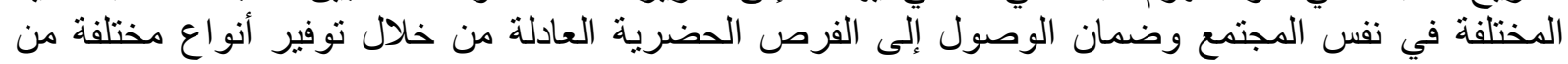

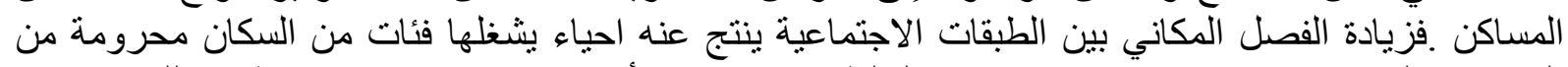

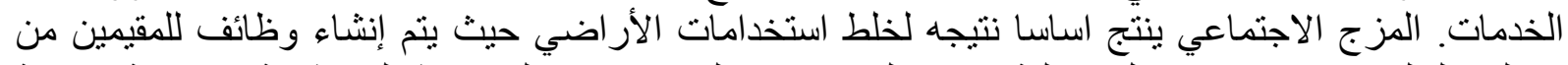

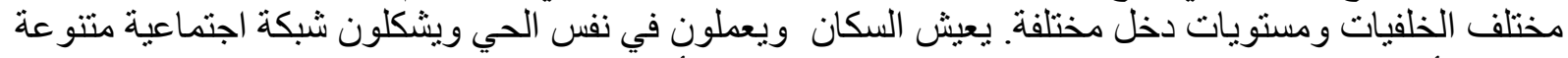

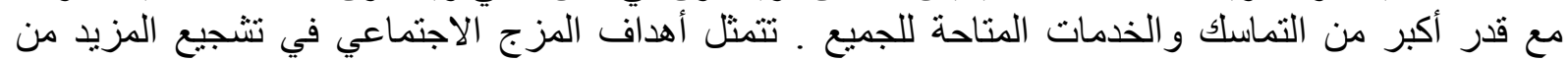

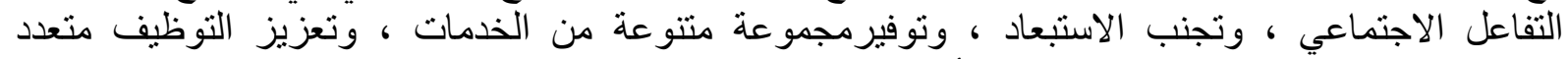

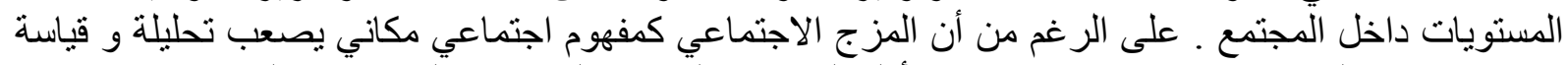

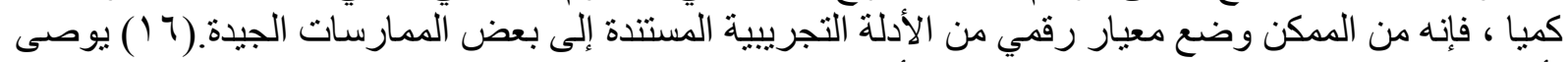

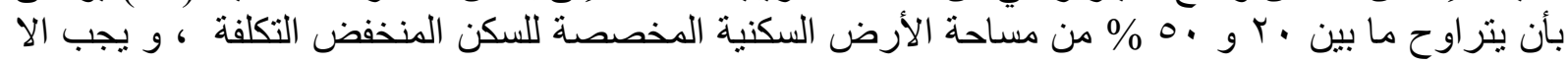

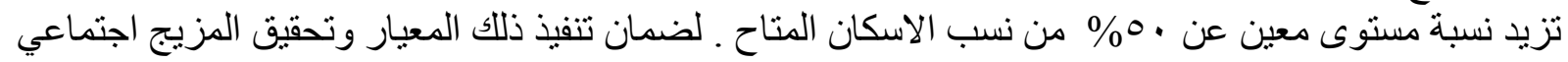

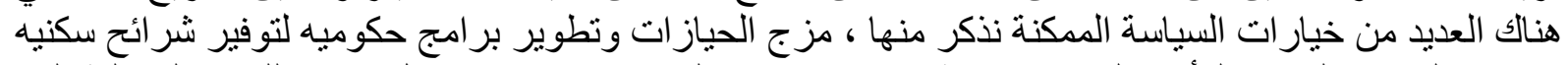

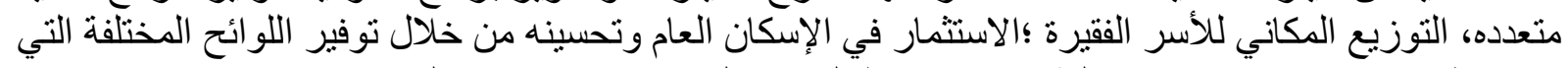

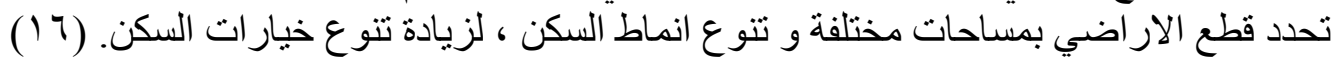




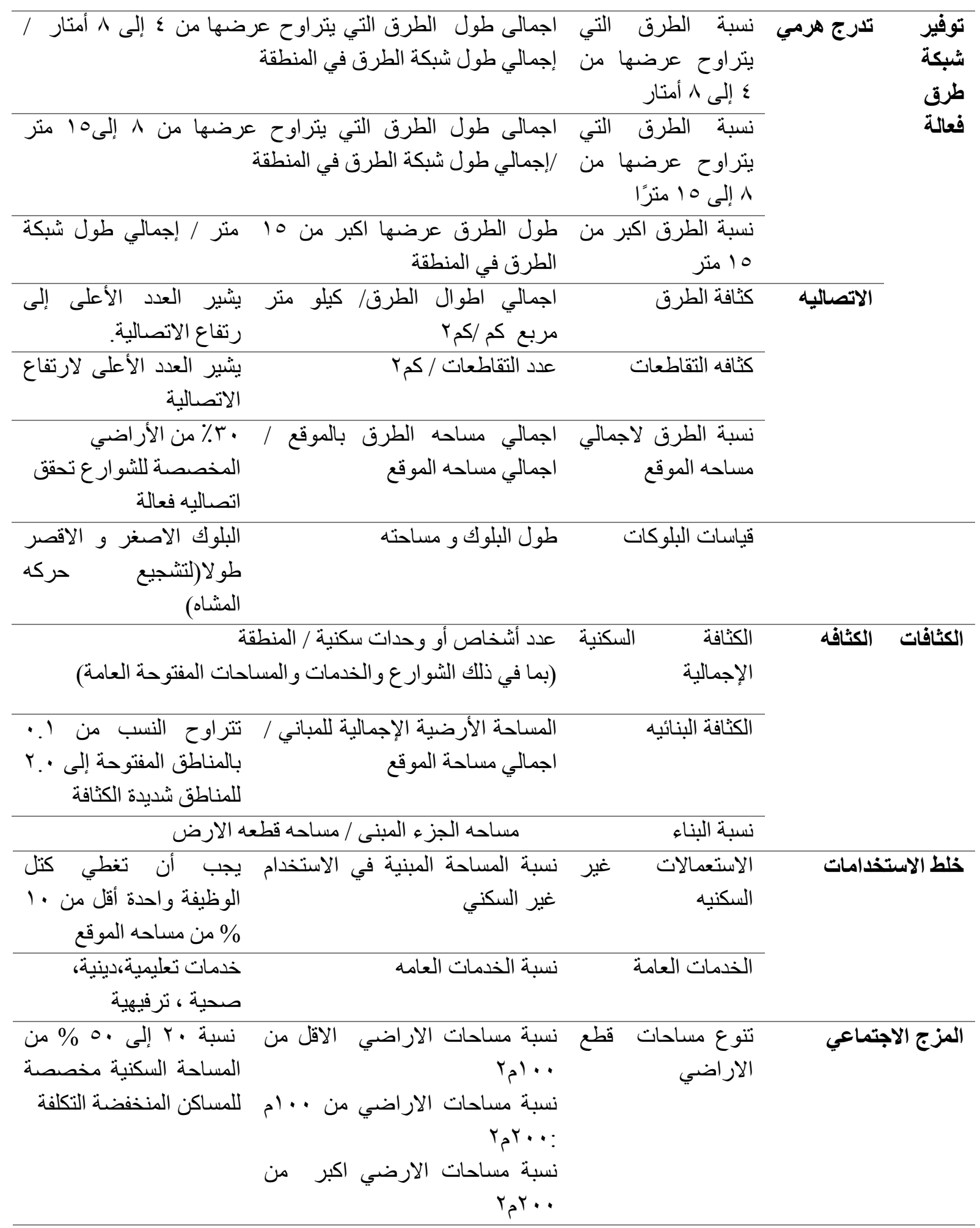

الجدول (1) المعايير المستخدمة لقياس مبادئ التخطيط الحضري المستلتم

Davidson,(1983),Acioly\&Davidson,(1996),Habitat,U. N.(2012), Mboup, (2013), المصدر : الباحث بتصريف عن

Dehghanmongabadi\& Shirkhanloo, (2014), Habitat, U. N. (2014), UN-Habitat. (2016 
r- باطق الإسكان غير الرسمي ( غير المخططة ) : يعرف قانون البناء المصري مناطق الإن الاسكان غير الرسمي (غير الرئ المخططة) : بانها المناطق التى لم ينم إنشاؤها

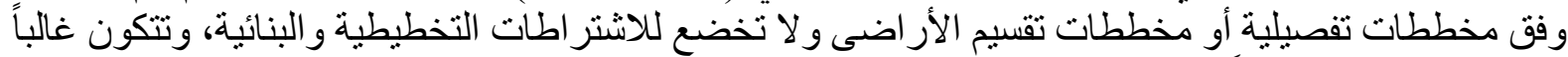

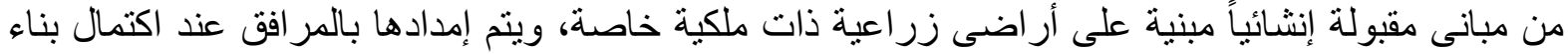

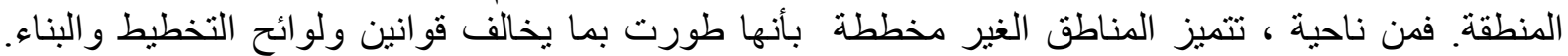

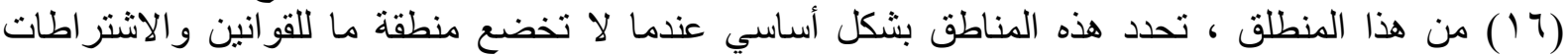

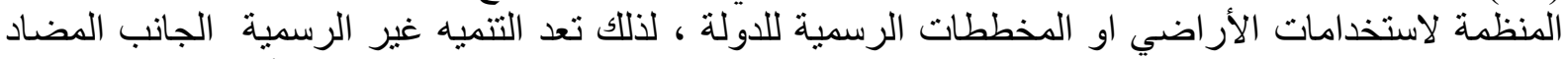

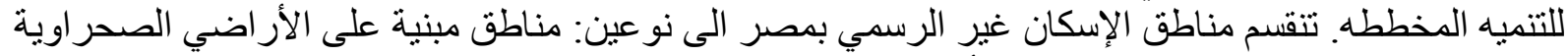

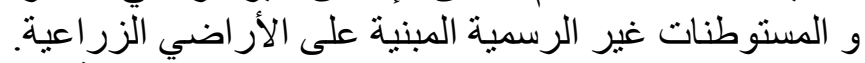

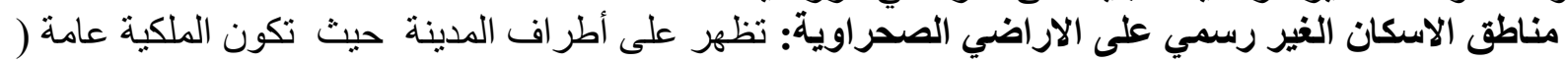

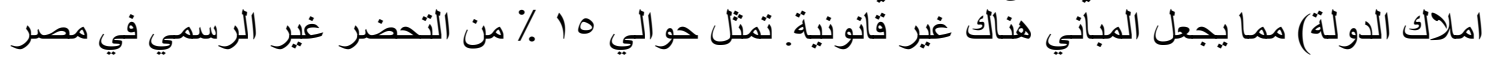

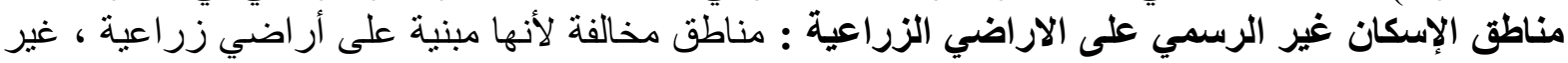

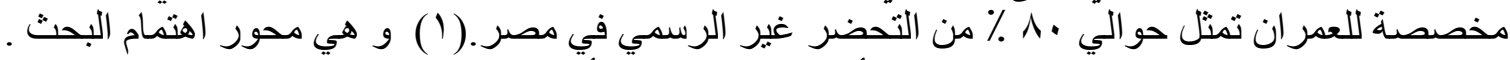

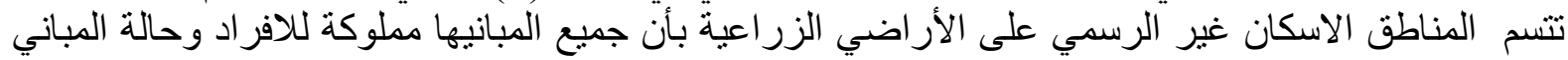

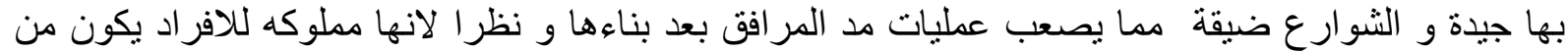

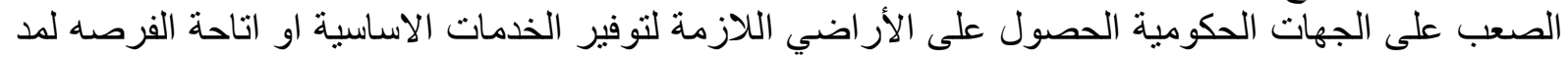

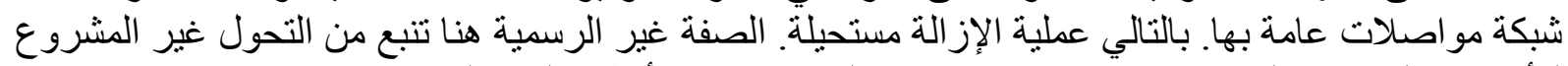
للأراضي الزر اعية إلى الإسكان، فضلا عن عند عدم الالتزام بقو انين و أنظمة البناء الرسمية .

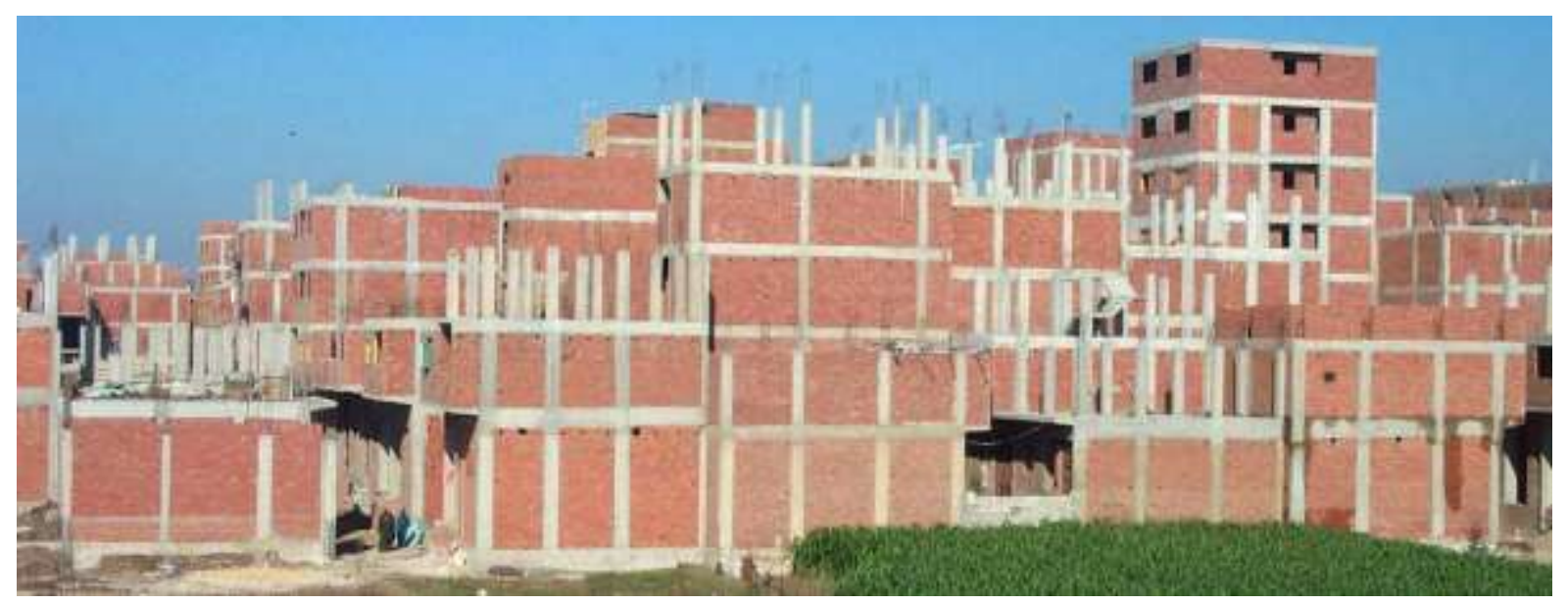

$$
\begin{aligned}
& \text { الصورة (1) مناطق الاسكان غير الرسمي على الاراضي الزراعية }
\end{aligned}
$$

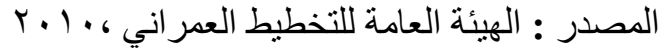

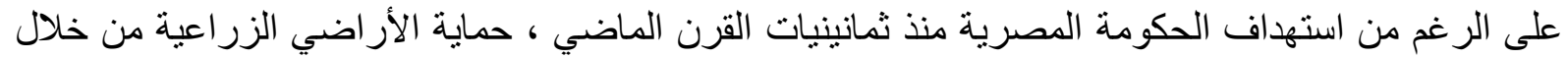

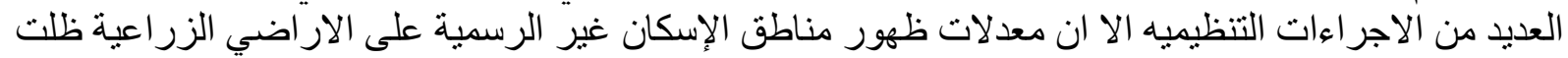

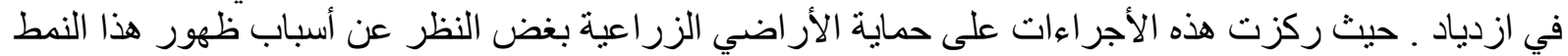

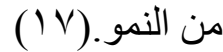

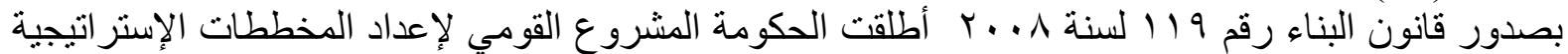

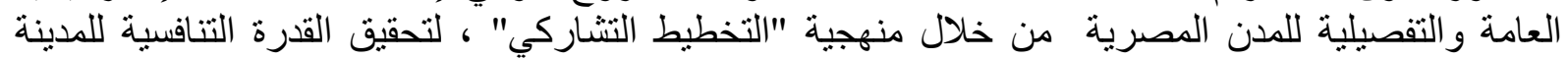

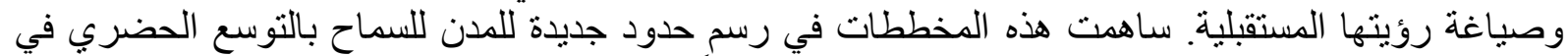

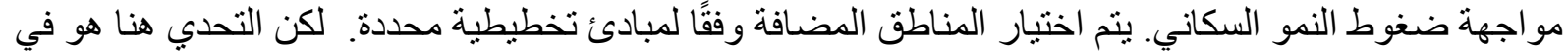
كيفية إعداد المخططات التفصيلية لمناطق الامتداد المضافة للحيز العمراني للمدينة . ينظم قانون البناء البناء الموحد

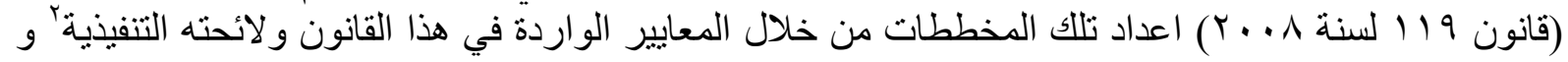




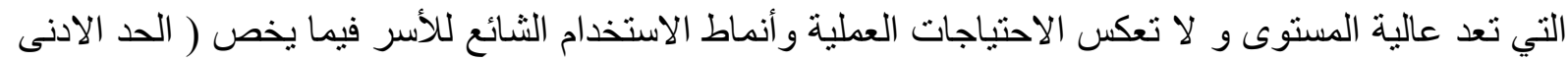

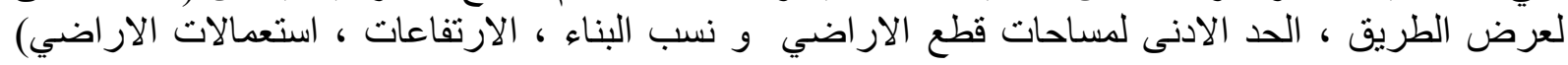
لما كان الهدف الرئيسي لعمليات النمو العمر اني للمدن هو توفير بيئة عمر انية ملائمة من خلال تحقيق مبادئ التنمية المستدامة لذلك فان الخطوه الاولى للوصول لمعايير تخطيطية اكثر ملائمة للاحتياجات الفعلية هي تحديد

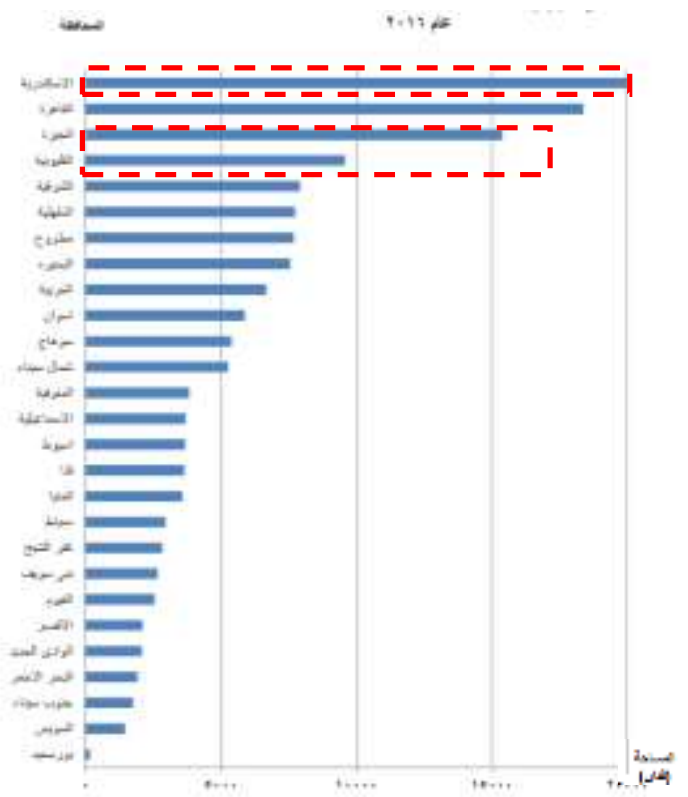

الثكل ( ) ) ترتيب محافظات مصر حسب نسب المناطق الغير مخططة

المصدر : الجهاز المركزي للتعبئه العامه و

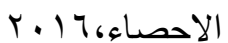

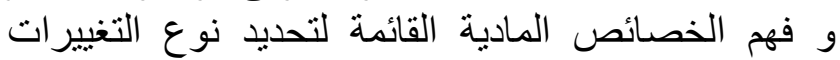
المطلوبة بهذه المعاييرلتحقيق تلك المبادئ من خلال التهن التبار

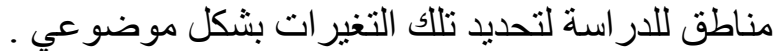

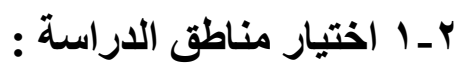

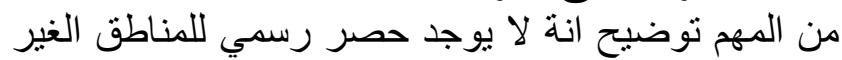

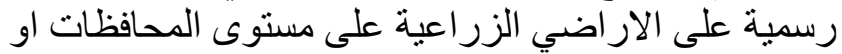

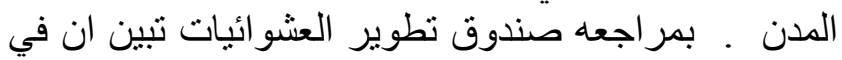

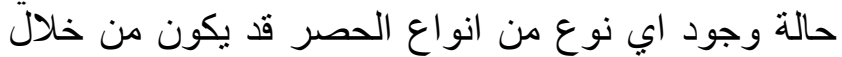

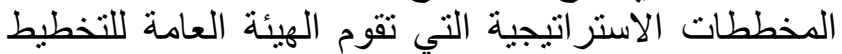

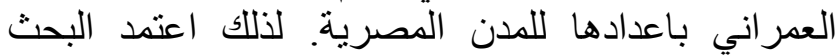

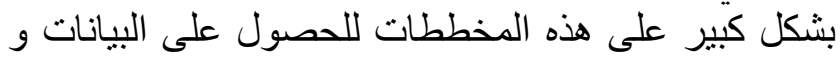

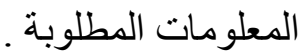
تم اختيار مناطق الدر اسله على مرحلتين

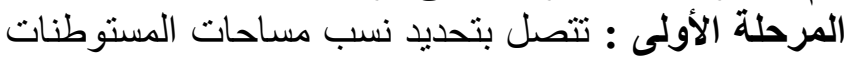

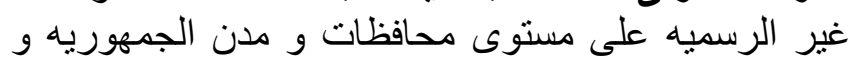
ترتيبها من الاعلى للاقل في المساحهاه و و عدد السكان

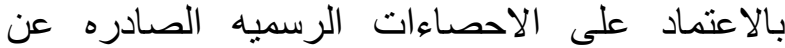

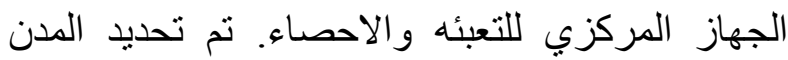
الاعلى في كل محافظه في المناطق الغينه الغير مخططه

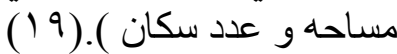

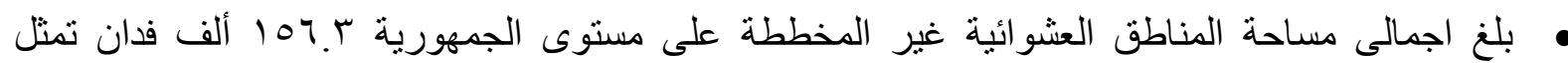

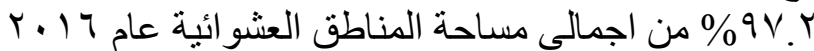

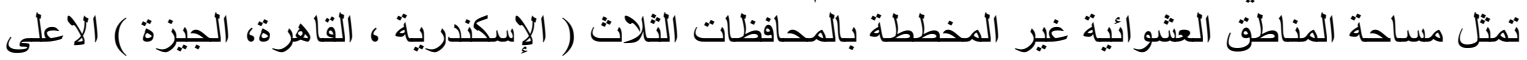

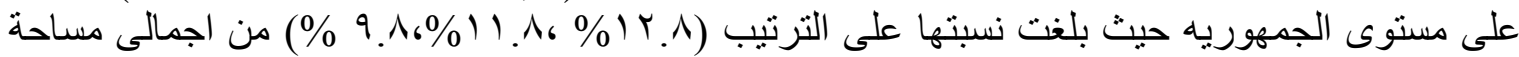
المناطق غير المخططة بالجمهوريه .

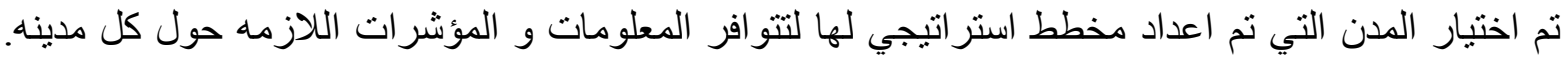

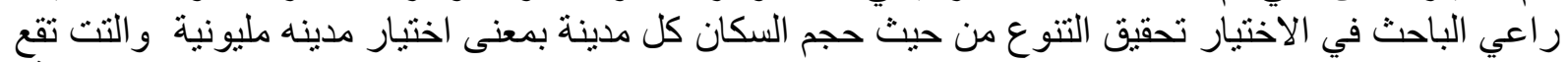

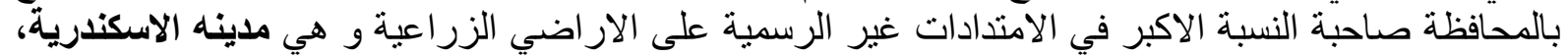

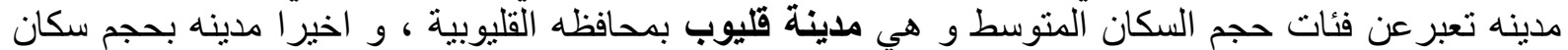

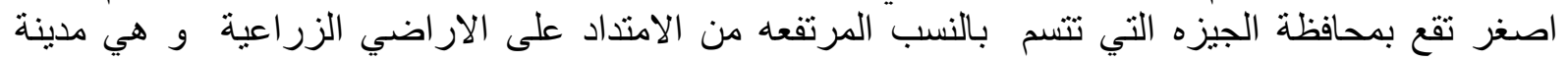
كرداسها . المرحلة التانيه : نم دراسه المخططات الاستر اتيجية للمدن المختارة و مر اجعه الدراسات الخاصة بمناطق

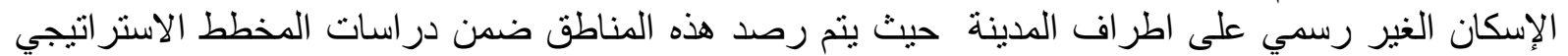

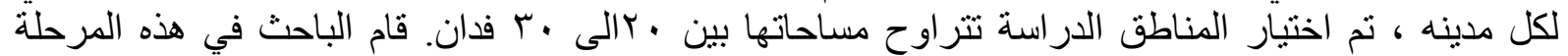

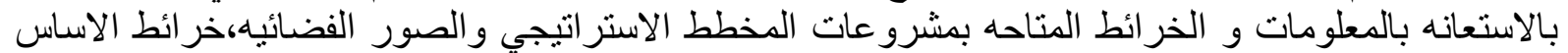

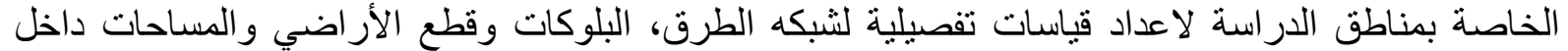


ب ـ ا ـ ا منطقة الاراسة رقم (1 ) بمدينه الاسكندرية

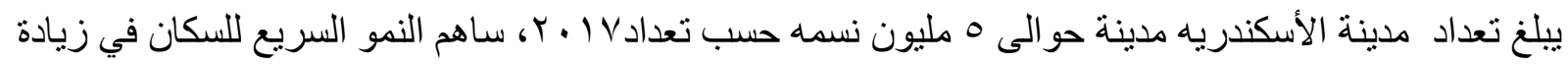

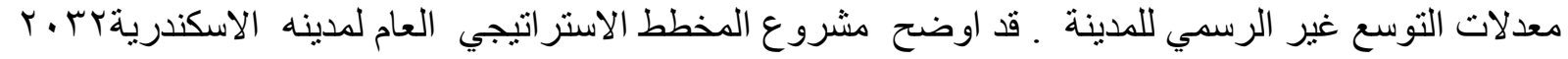

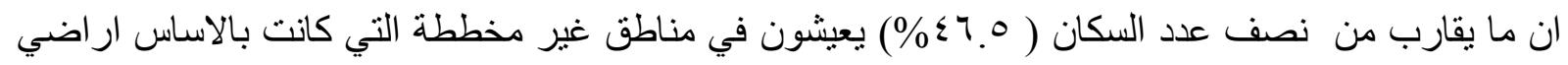

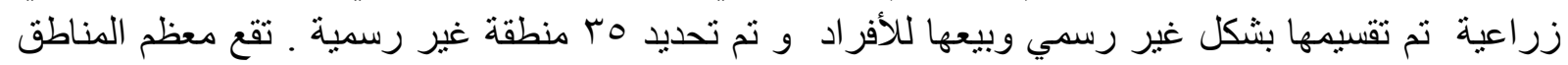

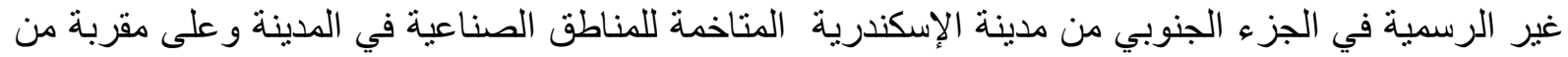

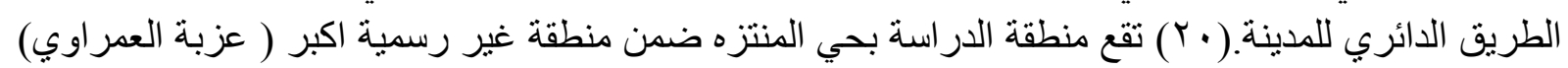

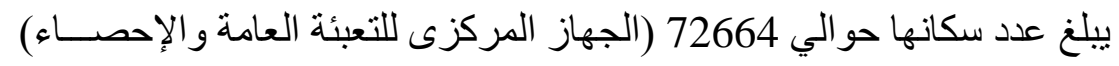

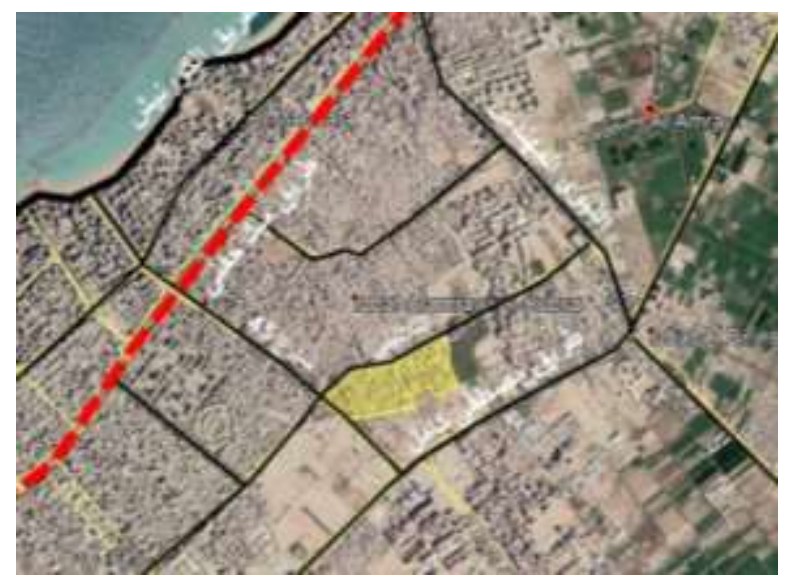

خريطة (ץ) موقع منطقة الاراسة بمدينة الاسكندرية المصدر : الباحث بندين

خريطة (1) مناطق الاسكان الغير رسمي بمدينة الإسكندرية

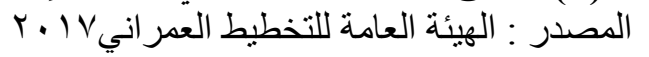

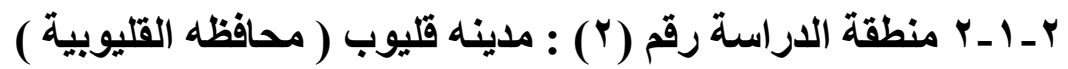

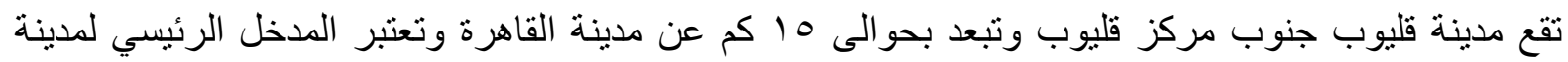

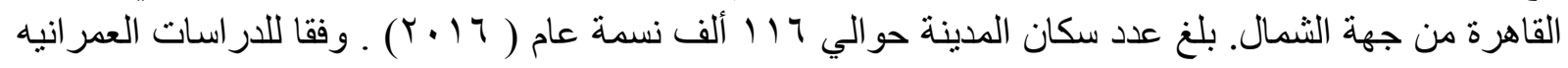

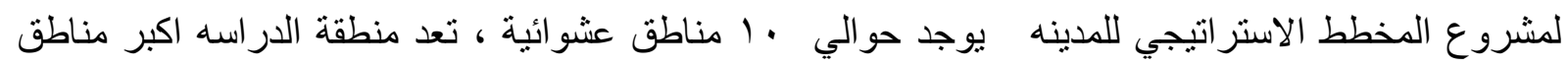

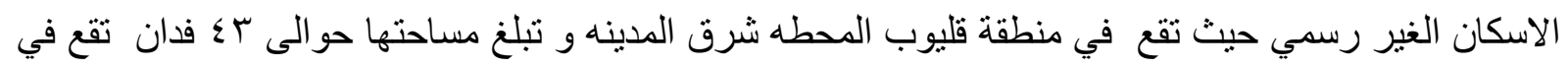

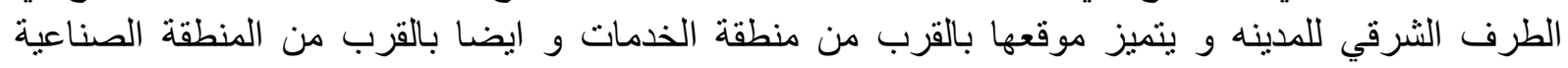

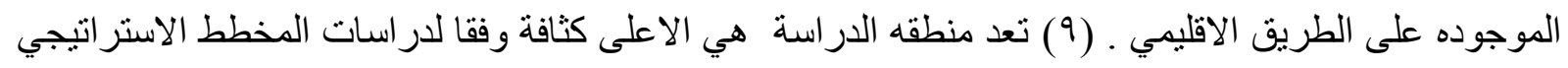
لكدينه نتيجه للتعدي المستمر علي الار اضي الزر التية.
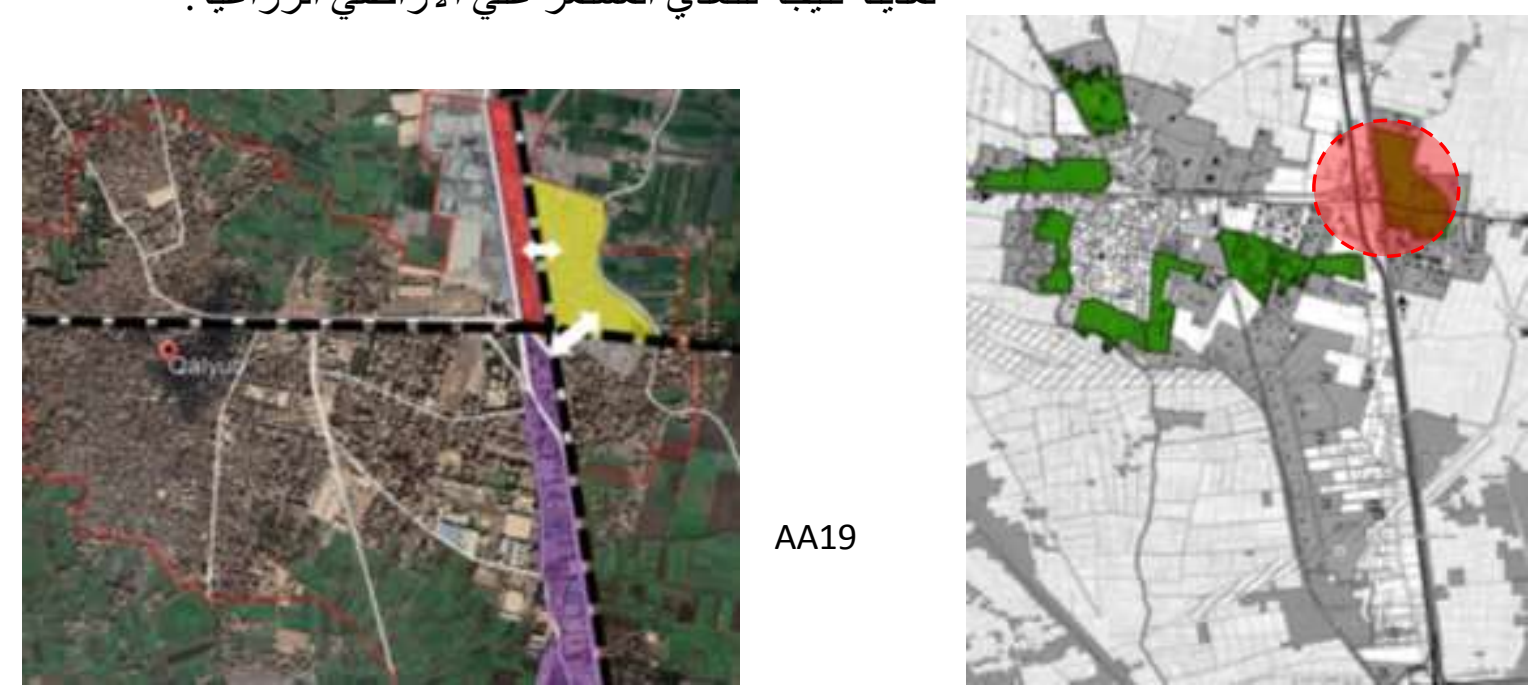


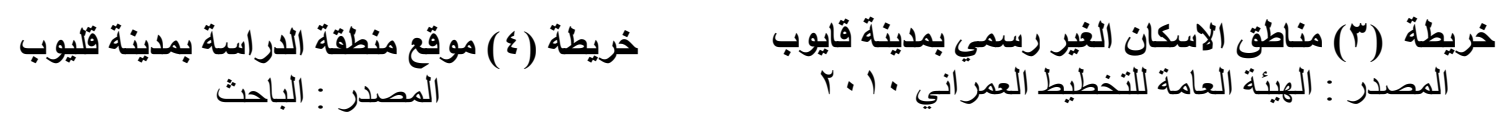

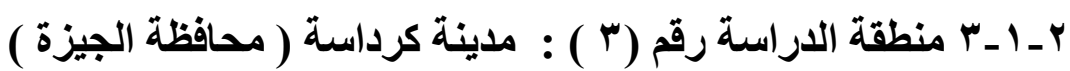

تقع مدينة كرداسة في الجزء الجنوبى من مركز كرداسة وجنوب غرب الكتلة الحضرية لمدينة الجيزة محصورة

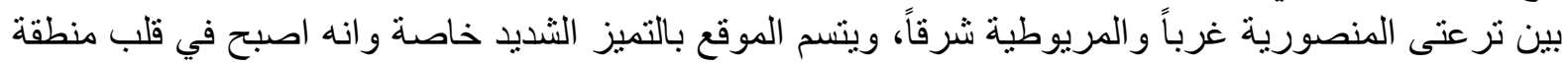

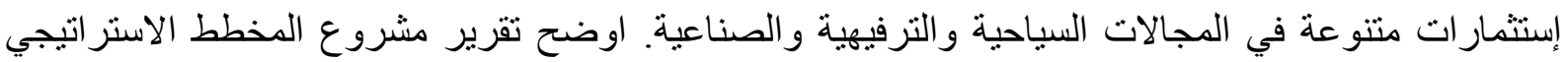

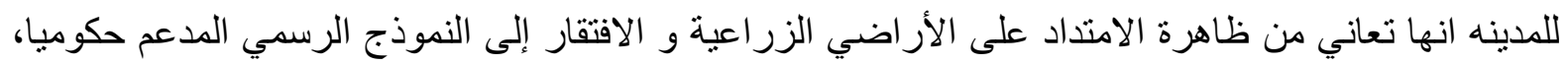

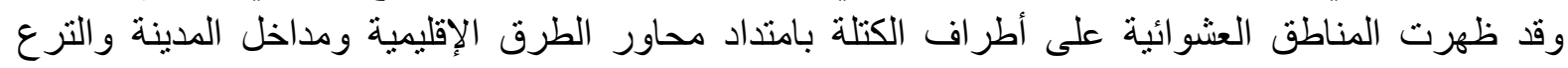

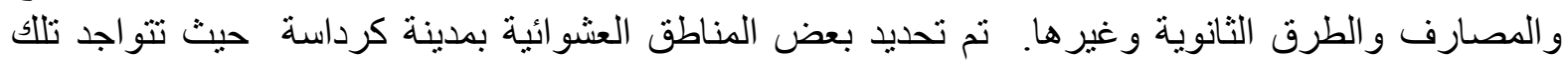

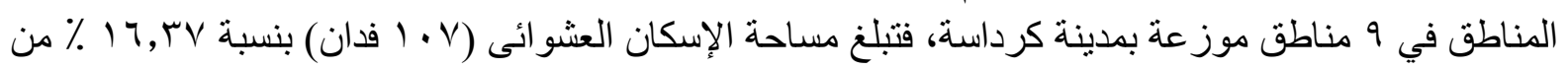

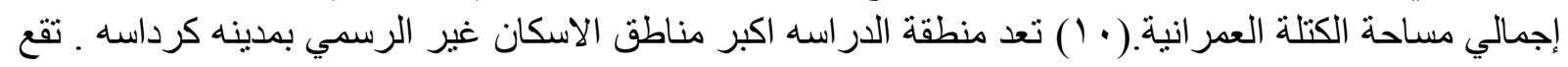
و ت تبلغ

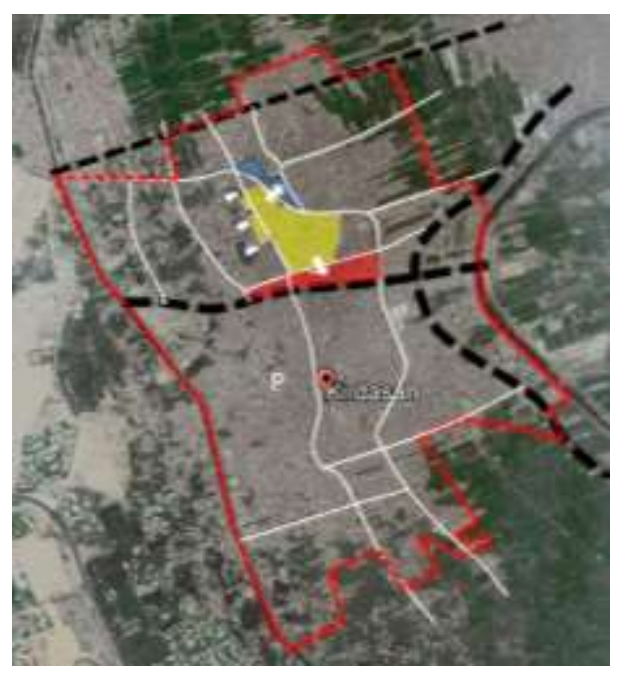

خريطة (7) موقع منطقة الاراسة بمدينة كرداسة المصدر : الباحث منطة الرئ

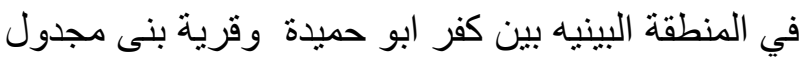

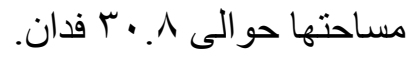

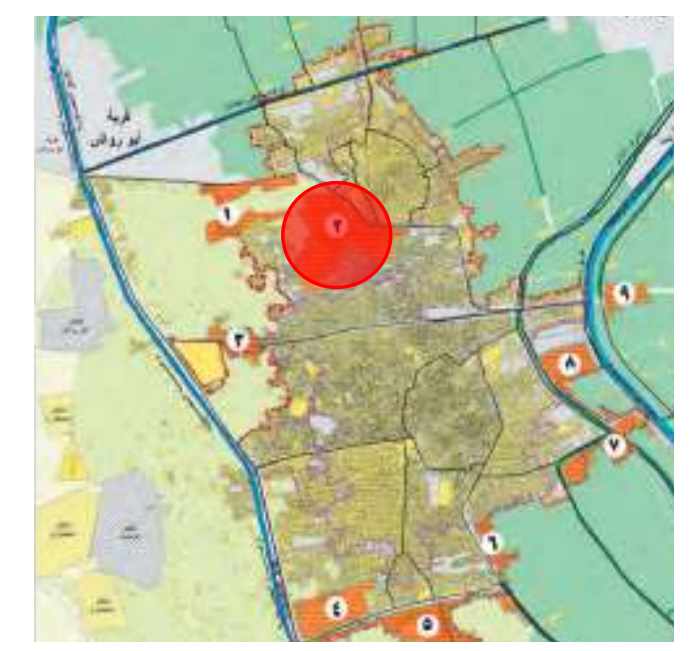

خريطة (0) مناطق الاسكان الغير رسمي بمدينة

\section{r- تحليل الخصائص المادية للبيئة}

العمرانية بمناطق الاراسة بالقياس على معايير التخطيط الخضري المستدام :

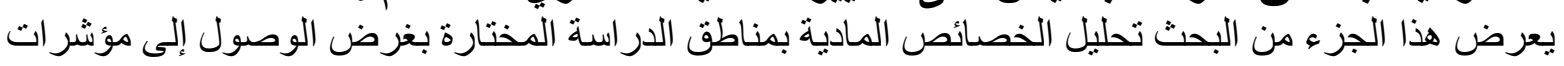
و مبادئ تساهم فى صياغة اسس و معايير موضو عية لكيفية وضع معايير تخطيطية لوضع مخططات تفصيلية 
لمناطق الامتداد العمر اني تحقيق مبادئ الاستدامة الحضرية تأخذ بعين الاعتبار السمات الواقعية القائمة و لا

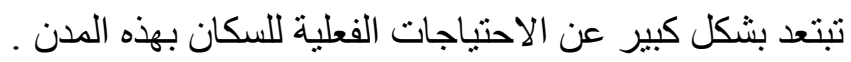

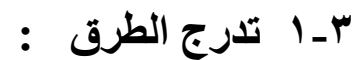

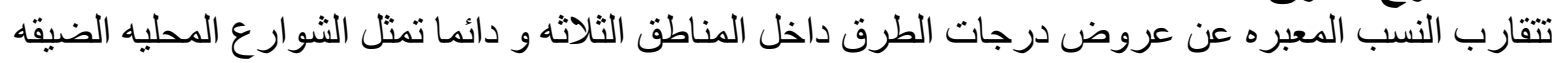

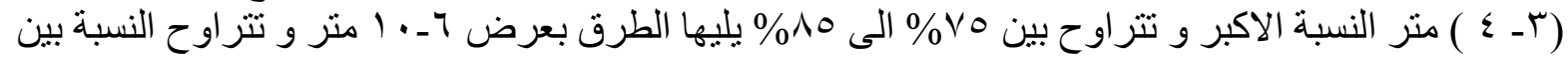

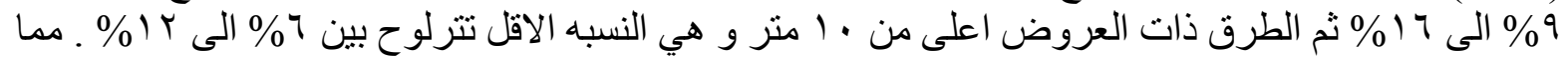

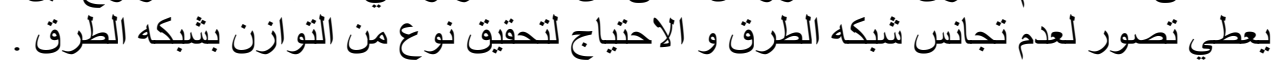

\section{: r-r \\ تم قياسها عموما ب باله ب فياسات اساسيه :}

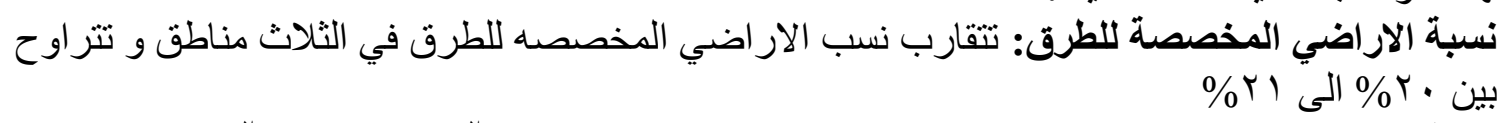

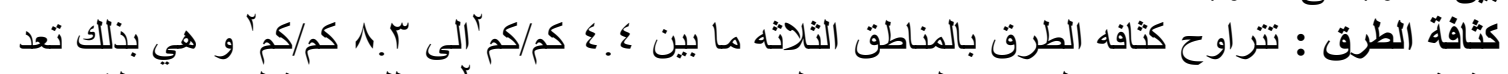

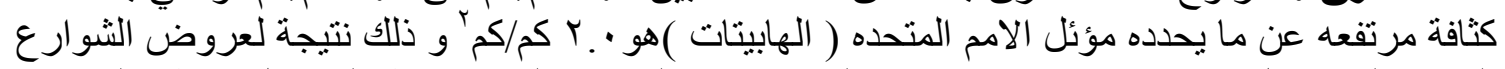

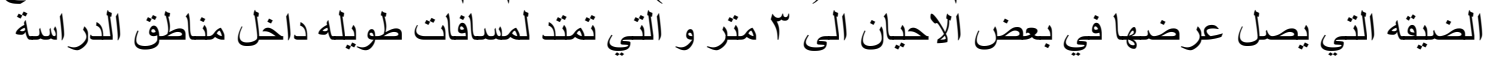

كثافة التقاطعات و ابعاد البلوكات و تثجيع حركه المشاة : ترتفع كثافة التقاطعات في مناطق الدراسه

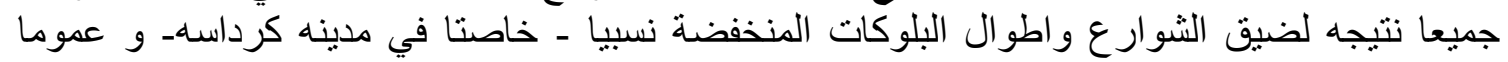

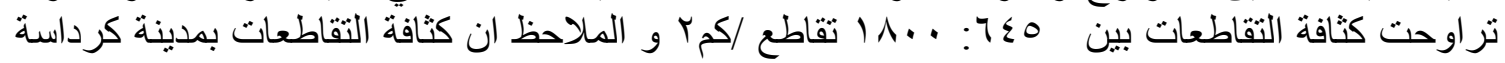

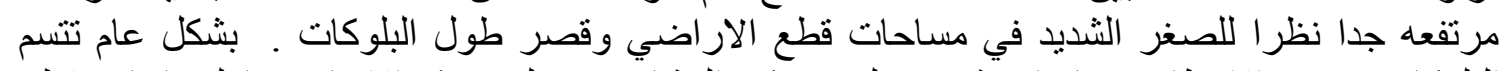

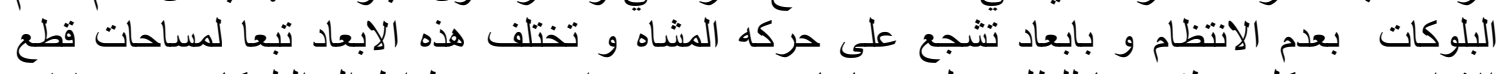

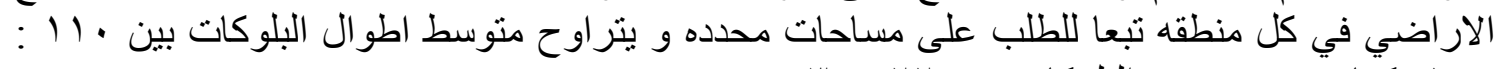

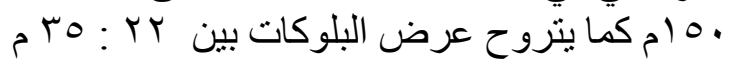

r. r الكثافات

الكثافات الاجماليه و الصافات الكافيه:

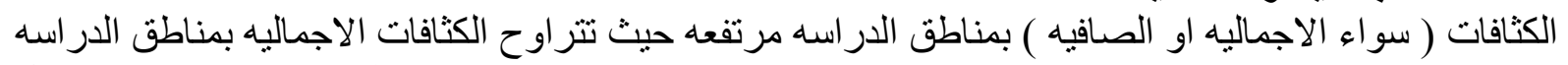

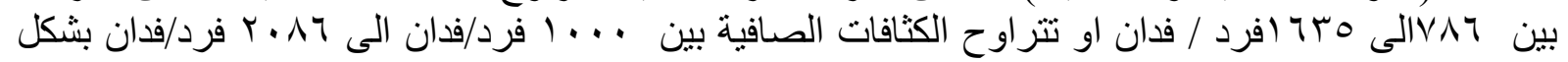

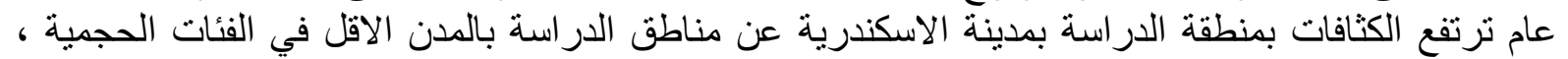

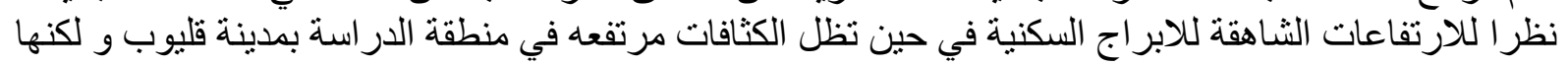

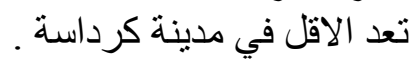

الكثافة البنائيه و نسب البناء

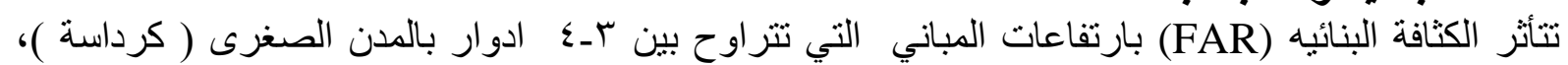

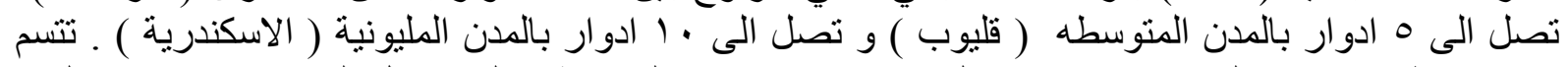

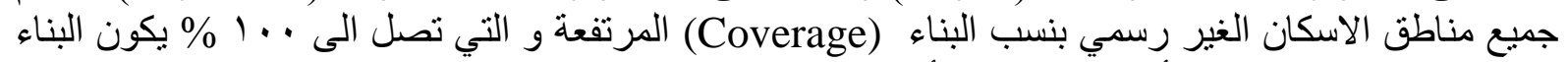

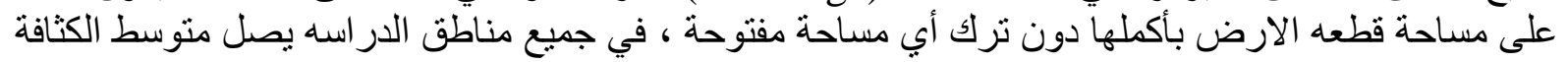

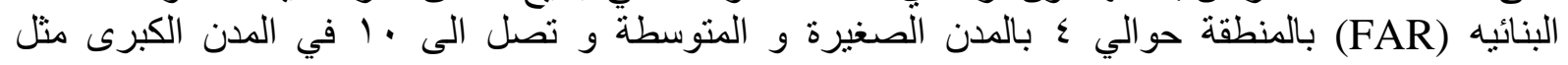

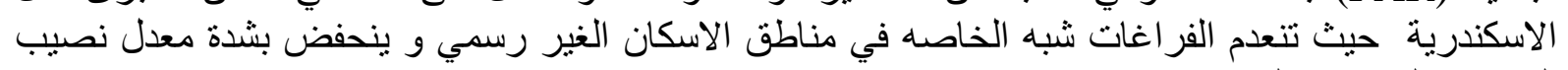

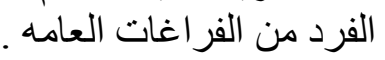

بـ ـ استعمالات الار اضي 
يغلب على مناطق الدراسه الاستخدام السكني ، السكني التجاري و لا تتوفر الخدمات تعليميه في كل الحالات داخل

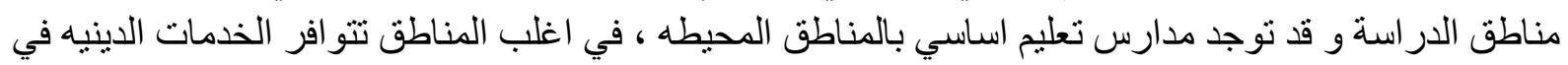

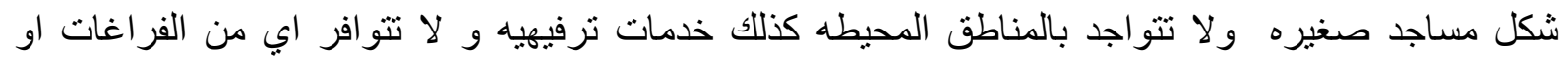

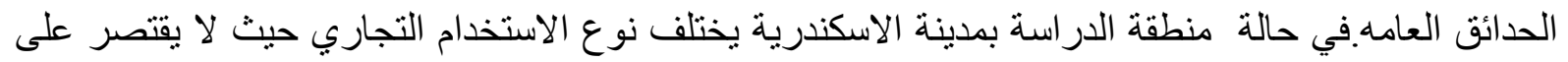
محلات لبيع الاحتياجات اليوميه ( سوبر ماركت ) و لكن نظهر محلات ماتهة ملابس، المكتبات ـ المطاعم كافيتريات

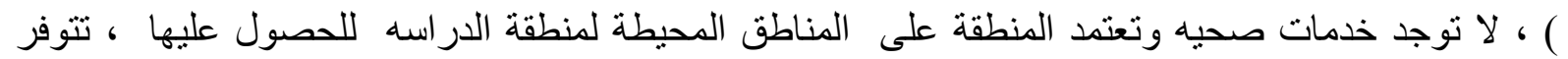

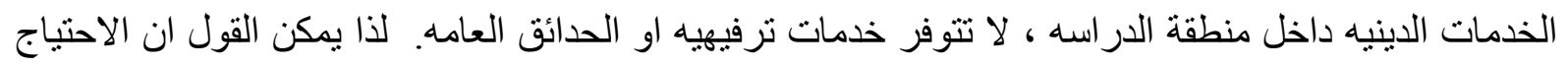

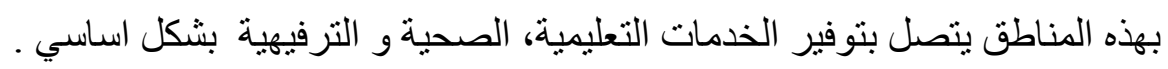

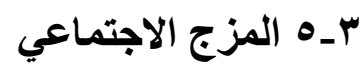
يتصل قياس المزج الاجتماعي مكانيا بتحقيق التنوع في مستويات الاسكان و نم قياسه من خلال التنوع في

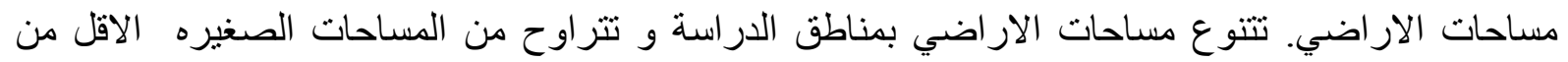

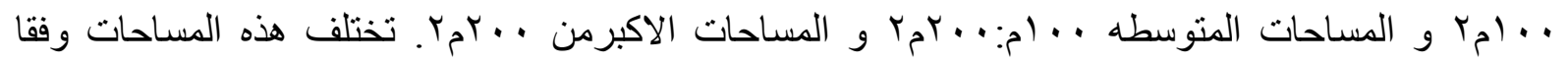

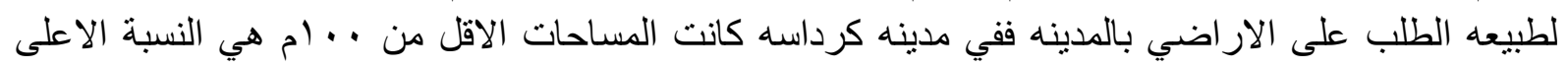

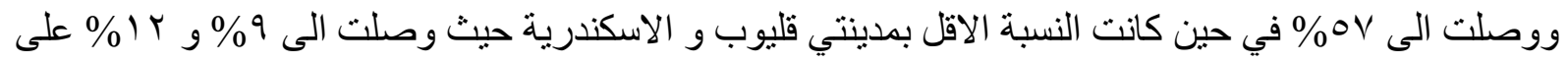

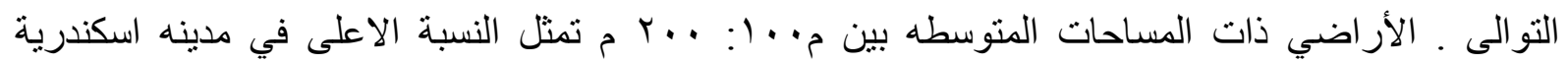

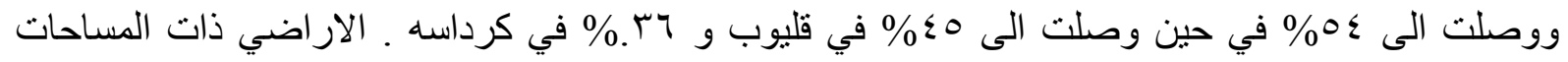

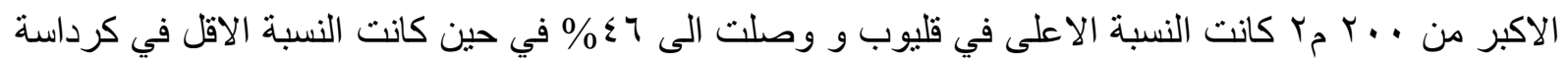

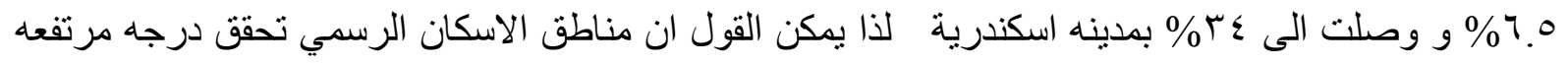

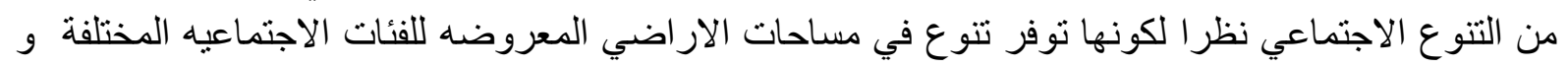

الجدول (r) قياس معايير استدامه البيئه العمرانيه للمناطق الغير رسميه بمناطق الاراسه المختاره تختلف بحسب طبيعه الطلب بكل مدينه.
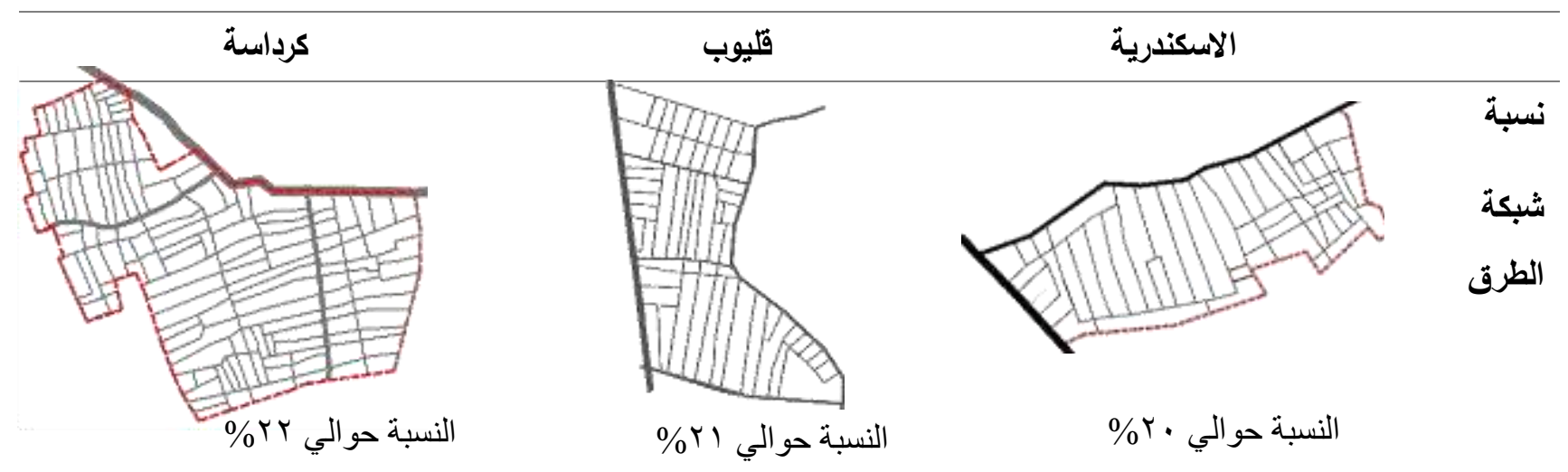


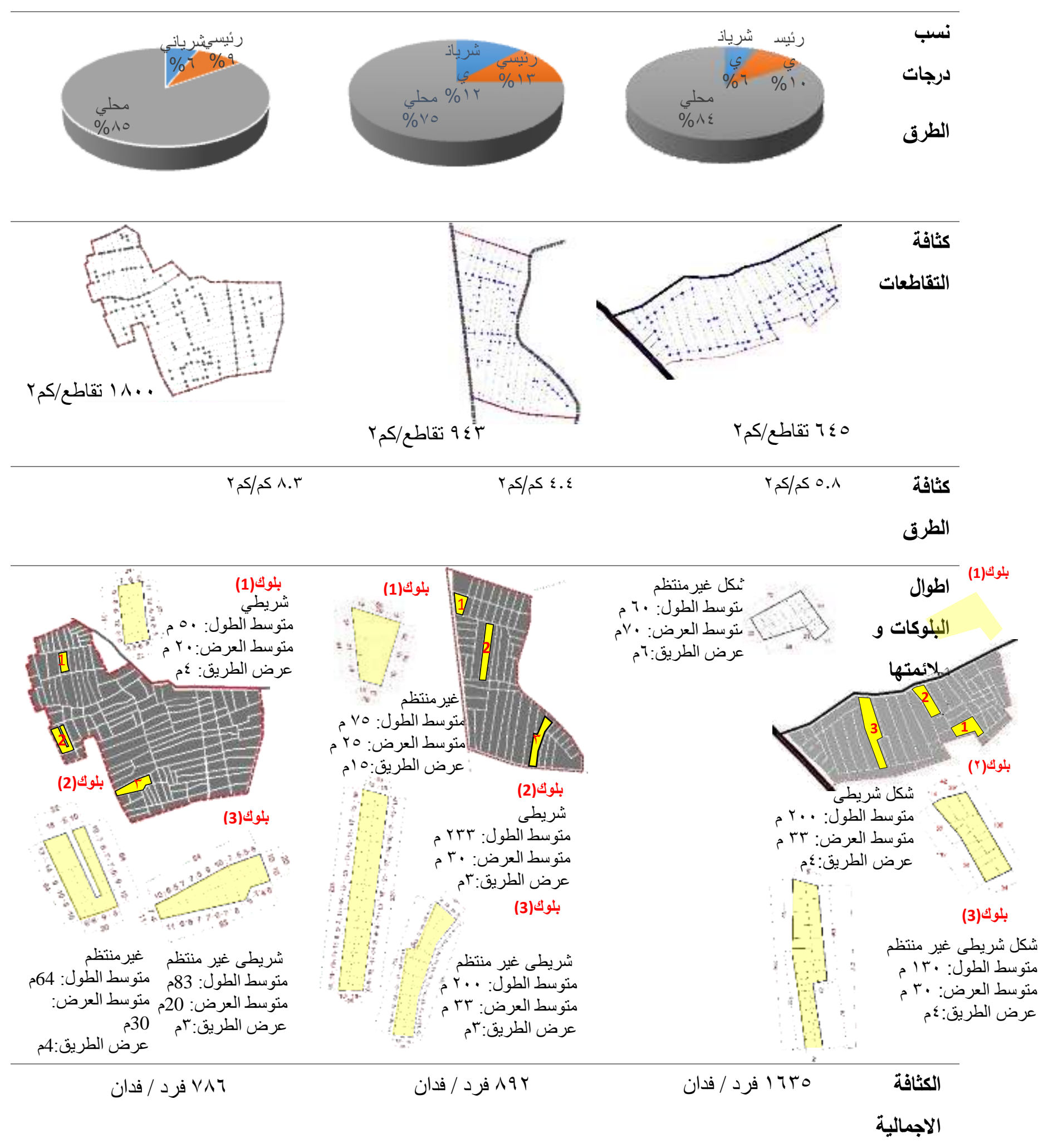




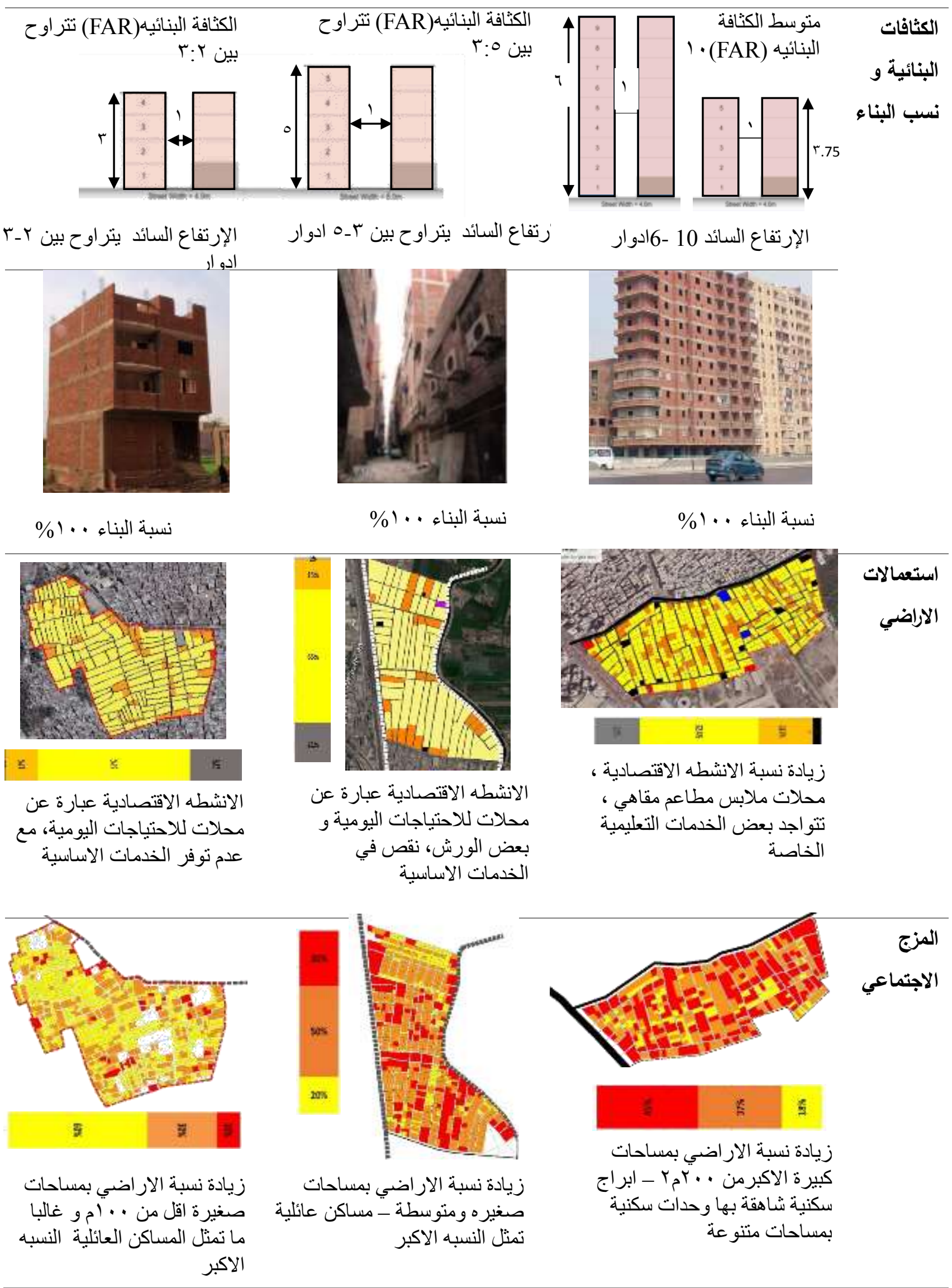




\section{ع - التتائج و التوصيات:}

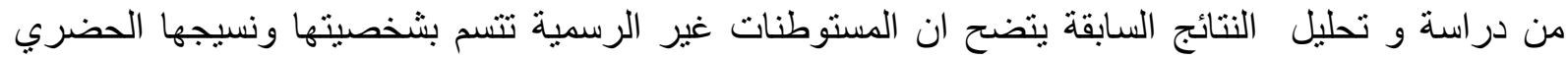
المتكرر في جميع مناطق الدر اسة . الا ان هناك بض الاختلافات المتصلة بالظروف الاجتماعية و الاقتصادية لكل مدينه .

حيث تثابهت جميع المناطق في بعض السمات مثل الافتقاد للتندرج الملائم لشبكة الطرق ، مع تحقق درجة اتصالية عالية من حيث كثافة الطرق و التقاطعات. جميع المناطق اتسمت بالملائمة لحركة المشاة بحسب قيات فياسات

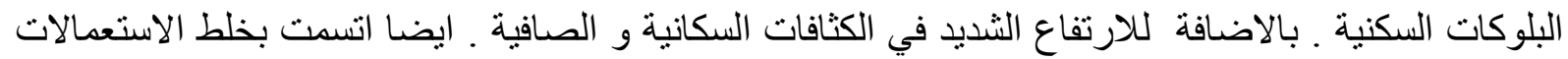

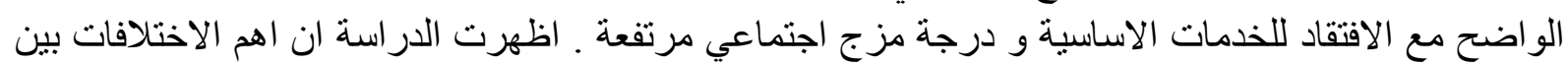

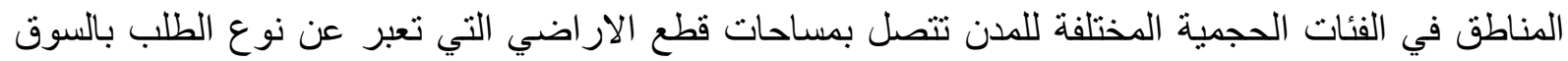

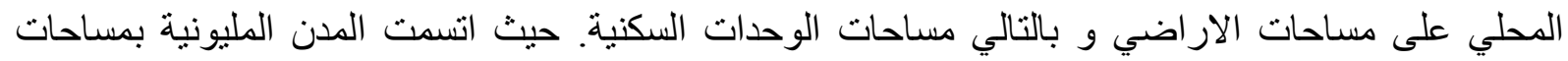

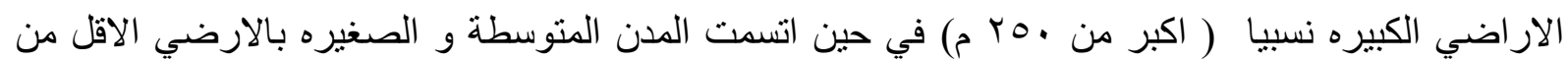

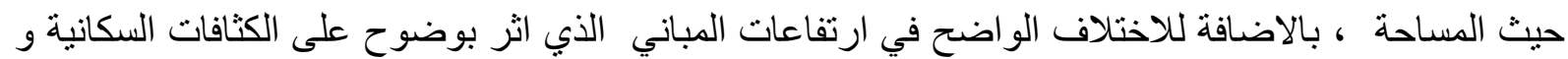

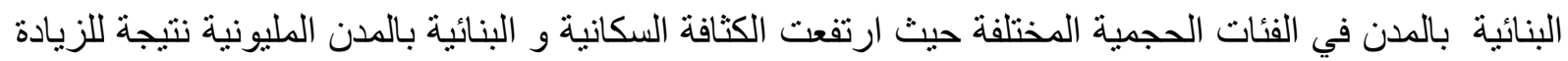

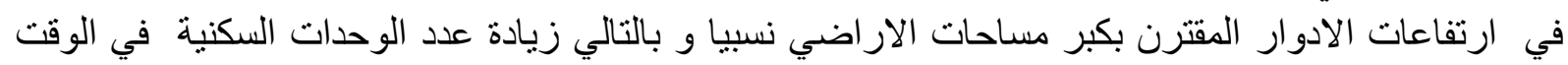

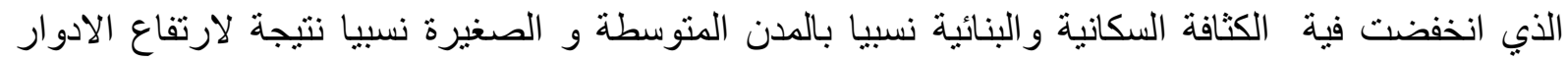

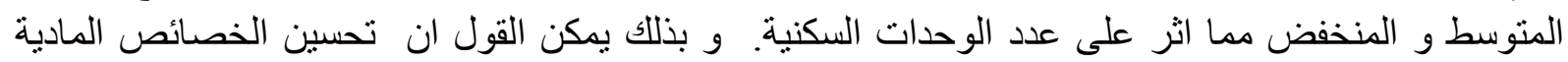

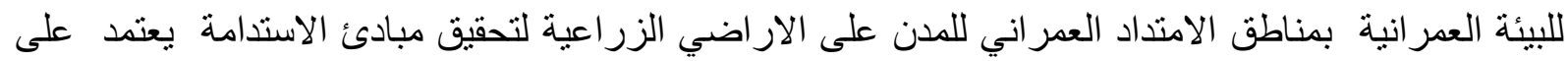

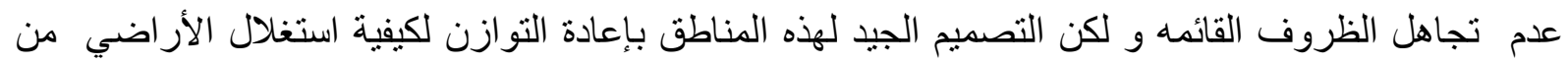

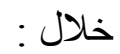

1 - زيادة نسب الار اضي المخصصة للطرق فقط بالمعدل الذي يسمح بتحقيق التدرج الهرمي المطلوب.

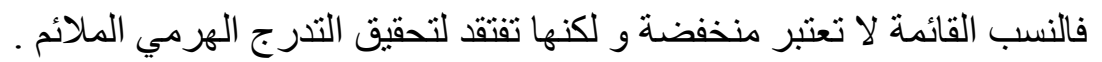
r- ـ ليس بالضرورة توحيد الحد الادنى لعرض الطريق في جميع المدن و لكن بمكن تحقيق ذلك من خلال

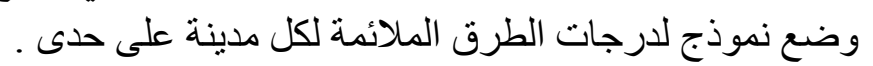

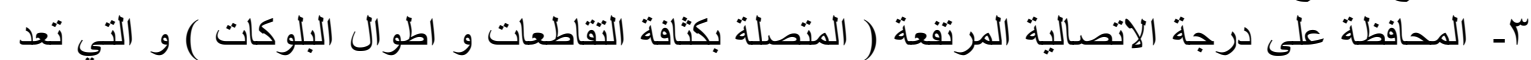
ملائمة لحركة المشاة كما هو قائم حاليا.

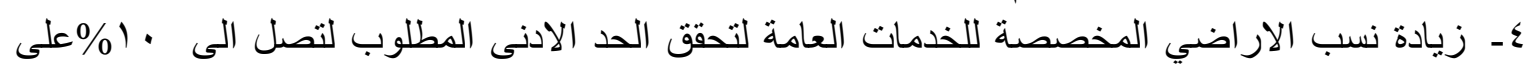

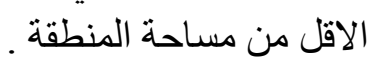

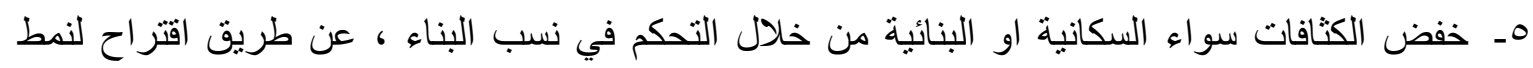

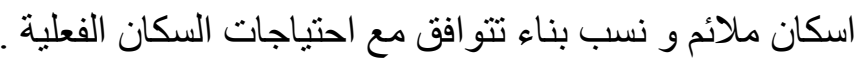

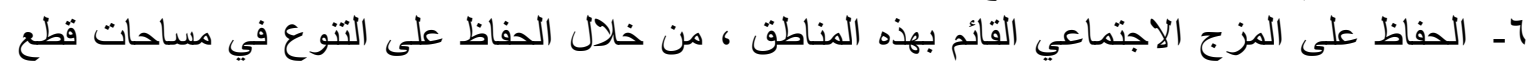
الار اضي

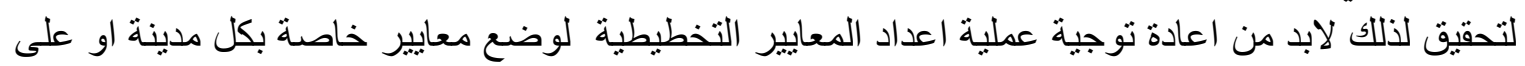

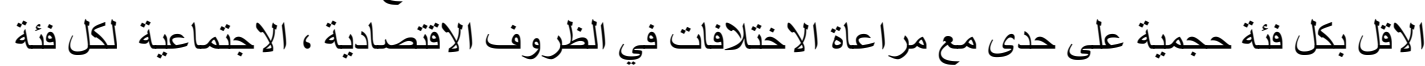

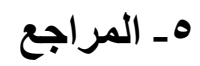

1. Khalifa, M. A. (2011). Redefining slums in Egypt: Unplanned versus unsafe areas. Habitat International, 35(1), 40-49. 
2. Khalil, H. E. (2010). New Urbanism, Smart Growth and Informal Areas: A Quest for Sustainability. Sustainable Architecture \& Urban Development, 137156.

3. Albayrak, A. N., \& Eryilmaz, Y. (2017). Urban Growth in Sustainability Perspective. Int'1 Journal of Advances in Agricultural \& Environmental Engg.(IJAAEE), 4(1).

4. Habitat, U. N. (2014). A new strategy of sustainable neighborhood planning: Five principles. Nairobi, Kenya: United Nations Human Settlements Programme.

5. Mboup, G. (2013). Streets as public spaces and drivers of urban prosperity. United Nations Human Settlements Programme (UN-Habitat).

6. United Nations Human Settlements Programme (UN-Habitat), 2016. Remaking the urban mosaic: Participatory and inclusive land readjustment. Nairobi, Kenya.

7. Mboup, G. (2013). Streets as public spaces and drivers of urban prosperity. United Nations Human Settlements Programme (UN-Habitat).

8. Mozas, J., \& Fernandez Per, A. (2004). DENSITY: new collective housing. Edition $\mathrm{a}+\mathrm{t}$.

9. Sivam, A., \& Karuppannan, S. (2012). Density, design and sustainable residential development (Doctoral dissertation, Earthscan).

10. Cheng, V. (2009). Understanding density and high density. In Designing HighDensity Cities (pp. 37-51). Routledge.

11. Davidson, F. (1983). Urban projects manual (pp. 37-43). G. Payne (Ed.). Liverpool: Liverpool University Press.

12. Sivam, Alpana \& Karuppannan, Sadasivam. ( $(\cdot 19)$. Density Design and Sustainable Residential Development.

13. http://densityatlas.org/measuring/metrics.shtml

14. Nabil, N. A., \& Eldayem, G. E. A. (2015). Influence of mixed land-use on realizing the social capital. HBRC Journal, 11(2), 285-298.

15. Dehghanmongabadi, A., Hoşkara, Ş. Ö., \& Shirkhanloo, N. (2014). Introduction to Achieve Sustainable Neighborhoods. International Journal of Arts and Commerce, 3(9), 16-26.

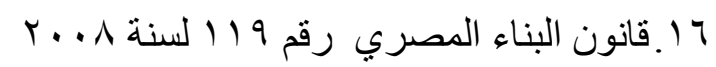

17. El-Hefnawi, A. Protecting agricultural land from urbanization or managing the conflict between informal urban growth while meeting the demands of the communities. In Third Urban Research Symposium on Land Development, Urban Policy and Poverty Reduction, Brasilia, Brazil, World Bank Institute of Applied Economic Research (IPEA) Brasilia, DF, Brazil, (2005, April). 
18. Habitat, U. N., Egypt Housing Profile, United Nations Human Settlements Programme (UN-Habitat) $201 \wedge$ https://unhabitat.org/egypt-housing-profile

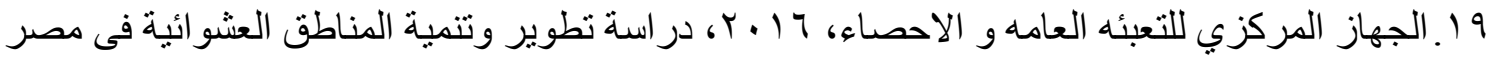

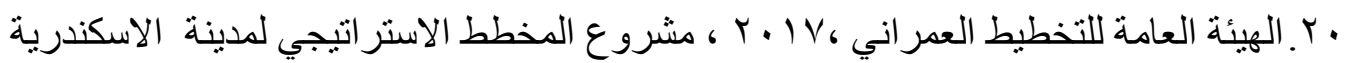

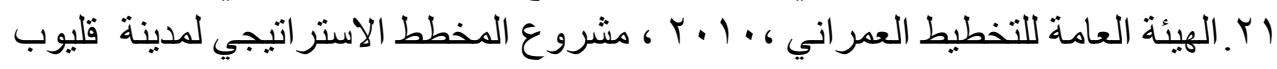

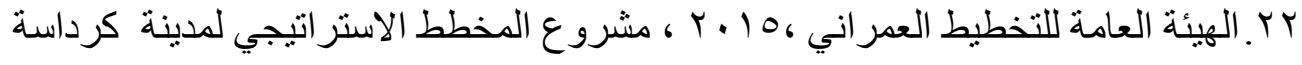

